Article

\title{
Activated Carbon and Carbon Quantum Dots/Titanium Dioxide Composite Based on Waste Rice Noodles: Simultaneous Synthesis and Application in Water Pollution Control
}

\author{
Xinyan Jin ${ }^{1}$, Ruijie Che ${ }^{1}$, Jie Yang ${ }^{1}$, Yan Liu ${ }^{1}$, Xinbao Chen ${ }^{1}$, Yunge Jiang ${ }^{1}$, Jiaqi Liang ${ }^{1}$, Shuoping Chen ${ }^{1, *}$ \\ and Heping $\mathrm{Su}^{2, *}$ \\ 1 College of Materials Science and Engineering, Guilin University of Technology, Guilin 541004, China; \\ 2120200261@glut.edu.cn (X.J.); 2120210253@glut.edu.cn (R.C.); 2120180167@glut.edu.cn (J.Y.); \\ 2120200279@glut.edu.cn (Y.L.); 3172042041419@glut.edu.cn (X.C.); 3192042041221@glut.edu.cn (Y.J.); \\ 3192042041306@glut.edu.cn (J.L.) \\ 2 College of Science, Guilin University of Technology, Guilin 541004, China \\ * Correspondence: 2012014@glut.edu.cn (S.C.); 2009059@glut.edu.cn (H.S.)
}

Citation: Jin, X.; Che, R.; Yang, J.; Liu, Y.; Chen, X.; Jiang, Y.; Liang, J.; Chen,

S.; Su, H. Activated Carbon and

Carbon Quantum Dots/Titanium Dioxide Composite Based on Waste Rice Noodles: Simultaneous Synthesis and Application in Water Pollution Control. Nanomaterials 2022, 12, 472. https://doi.org/10.3390/ nano12030472

Academic Editors: Piotr Kamedulski and Jerzy P. Lukaszewicz

Received: 22 December 2021

Accepted: 22 January 2022

Published: 29 January 2022

Publisher's Note: MDPI stays neutral with regard to jurisdictional claims in published maps and institutional affiliations.

Copyright: (c) 2022 by the authors. Licensee MDPI, Basel, Switzerland. This article is an open access article distributed under the terms and conditions of the Creative Commons Attribution (CC BY) license (https:// creativecommons.org/licenses/by/ $4.0 /)$.

\begin{abstract}
To achieve the full utilization of waste rice noodle (WRN) without secondary pollution, activated carbon $(\mathrm{AC})$ and carbon quantum dots/titanium dioxide (CQDs/ $\left.\mathrm{TiO}_{2}\right)$ composite were simultaneously synthesized by using WRN as raw material. Both of the two materials showed potential applications in water pollution control. The AC based on WRN displayed a porous spherical micromorphology, which could absorb heavy metal elements like $\mathrm{Pb}(\mathrm{II})$ and $\mathrm{Cr}(\mathrm{VI})$ efficiently, with a maximum equilibrium uptake of $12.08 \mathrm{mg} \cdot \mathrm{g}^{-1}$ for $\mathrm{Pb}$ (II) and $9.36 \mathrm{mg} \cdot \mathrm{g}^{-1}$ for $\mathrm{Cr}(\mathrm{VI})$, respectively. The adsorption of the resulted AC could match the Freundlich adsorption isotherm and the pseudo-second-order kinetics mode. On the other hand, the CQDs $/ \mathrm{TiO}_{2}$ composite based on WRN displayed a high efficient photocatalytic degradation effect on various water-soluble dyes such as methylene blue, malachite green, methyl violet, basic fuchsin, and rhodamine B under visible light irradiation, which showed better photocatalytic performance than commercial $\mathrm{TiO}_{2}$. The introduction of CQDs based on WRN to $\mathrm{TiO}_{2}$ could result in efficient electron-hole pair separation and enable more photogenerated electrons to reduce $\mathrm{O}_{2}$ and more photogenerated holes to oxidize $\mathrm{H}_{2} \mathrm{O}$ or $\mathrm{OH}^{-}$, which could cause stronger abilities in producing $\mathrm{O}_{2} \cdot-$ and $\cdot \mathrm{OH}$ radical and better photocatalytic activity.
\end{abstract}

Keywords: waste rice noodle; activated carbon carbon; quantum dots/titanium dioxide composite; water pollution control

\section{Introduction}

Cooking waste can cause potential pollution to the soil and water environment and provide a significant challenge to urban governance [1-3]. Nowadays, commercial treatments for cooking waste recycling are mainly anaerobic digestion [4-6], aerobic composting [7,8], landfill [9-11], incineration [12], and forage making [7]. Although cooking waste can be treated through the above strategy with large-scale industrialization, there are some fatal shortcomings, such as the mass occupation of land, high investment for equipment, low product profit margin, easy production of secondary pollution like greenhouse gases, and waste leachate $[1,13]$.

In recent years, hydrothermal carbonization has proved to be a new and effective method for cooking waste treatment [14-16], whose process is simple, environment friendly, requires mild conditions, results in near-zero emissions, and may provide functional carbon materials such as activated carbon (AC) [17] or fluorescent carbon quantum dots (CQDs) [18]. However, due to complicated compositions, the intermediate products of hydrothermal carbonization often display different physical chemical characters, which produce great difficulties for subsequent treatment. Thus, it is difficult to achieve the 
full utilization of cooking waste, and secondary pollution like waste water and residue is unavoidable.

The AC with a porous structure can effectively absorb various kinds of metal ions and is widely used in the treatment of wastewater [19]. For cost control and resource recycling, a wide variety of AC adsorbents derived from a natural products or organic waste have been reported in recent years, whose sources include coconut shell $[20,21]$, pecan shell [22], peanut shell [23], date pit [24], hazelnut husk [25], sagowaste [26], paper mill sludge [27], polygonum [28], crassipes root [29], and so on. On the other hand, nano titanium dioxide $\left(\mathrm{TiO}_{2}\right)$ is a commercial photocatalyst used in water and air pollution control [30-32]. However, pure $\mathrm{TiO}_{2}$ displays a wide band gap whose photogenerated electrons and holes are easy to combine again. Moreover, it has a low absorption and utilization rate of visible light whose wavelength is more than $380 \mathrm{~nm}$, which limits its application in visible light catalysis. As a new type of carbon nano-material, CQDs have many advantages, such as excellent stability against photobleaching, good water solubility, high biocompatibility, and relatively low toxicity [33-35] and can also be used as photoactive materials to generate reactive oxygen species under light radiation [36]. To date, CQDs-enabled photocatalysts are regarded as among the most efficient technologies to degrade organic pollutants in water [37-39]; for the introduction of CQDs to inorganic photocatalyst like $\mathrm{TiO}_{2}$ can effectively enhance energy absorption, promote electronic transition, produce more electron-hole pairs, and reduce the recombination of electron-hole pairs [40-42]. However, the current commercial CQDs are very expensive, which hinders the commercialization of the $\mathrm{CQDs} / \mathrm{TiO}_{2}$ composite.

Rice noodle is a traditional daily diet of local people in Guilin city, China. Therefore, a large amount of waste rice noodles (WRN) is produced in this city, with an output of over 70 tons per day. However, due to the underdeveloped economy of Guilin, the infrastructure, policy support, and capital investment in the recycling of catering waste are relatively limited. Most of the WRN is used as raw materials for low-degree fermentation feed, and the other part is directly discarded, which causes potential and long-term pollution to the soil and water environment. Therefore, it is necessary to explore an effective way to recycle WRN. Starch is the main organic component in WRN, which is easy to carbonize under hydrothermal conditions, so it has the potential to prepare functional carbon materials. In our previous works, we treated WRN by a hydrothermal method to obtain carbon spheres and CQDs and then blended the resulting carbon materials with polylactic acid (PLA), resulting in C/PLA and CQDs/PLA 3D printing composites, respectively $[43,44]$. Herein, in order to achieve the full utilization of WRN and obtain low-cost carbon materials for water pollution control, we design a new method for co-producing $\mathrm{AC}$ and CQDs $/ \mathrm{TiO}_{2}$ composite with WRN as raw materials (See Figure 1). More specifically, WRN was treated under hydrothermal conditions to form a mixture of precipitate (hydrothermal carbon powder, HTC powder) and liquid (CQDs solution), and then the HTC powder was produced as AC, while the CQDs solution could be used to synthesize $\mathrm{CQDs} / \mathrm{TiO}_{2}$ composite simultaneously. Furthermore, the obtained AC could absorb heavy metal elements, while the CQDs $/ \mathrm{TiO}_{2}$ composite displayed a high efficient photocatalytic degradation effect on water-soluble dyes, which could together form a wastewater treatment system. 


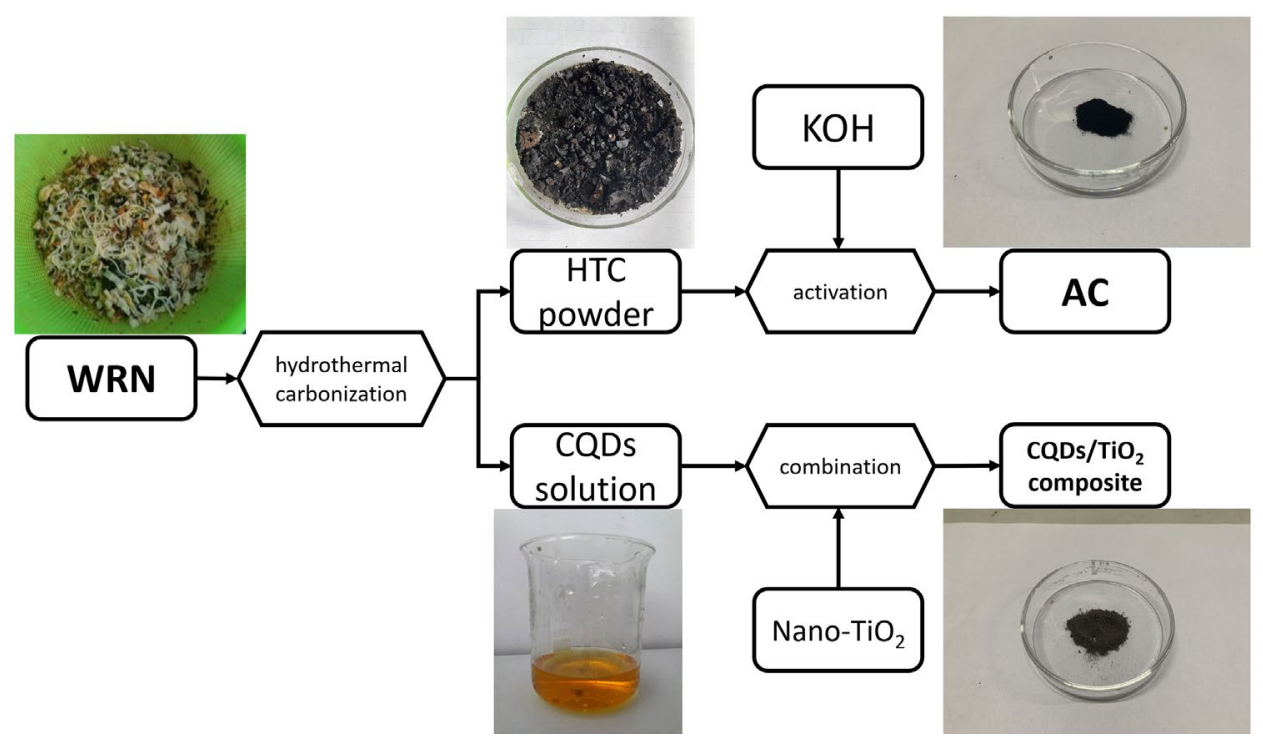

Figure 1. Schematic diagram of the simultaneous synthesis of $\mathrm{AC}$ and $\mathrm{CQDs} / \mathrm{TiO}_{2}$ composite.

\section{Experiment Section}

\subsection{Materials and Methods}

The waste rice noodle (WRN, main organic constituent: starch $21.36 \mathrm{~g} / 100 \mathrm{~g}$; protein $1.91 \mathrm{~g} / 100 \mathrm{~g}$; fat $0.4 \mathrm{~g} / 100 \mathrm{~g}$ ) was collected from the canteen of the Guilin University of Technology in Guilin, China. The sodium carboxymethyl cellulose (CMC-Na), potassium hydroxide $(\mathrm{KOH})$, hydrochloric acid $(\mathrm{HCl})$, potassium dichromate $\left(\mathrm{K}_{2} \mathrm{Cr}_{2} \mathrm{O}_{7}\right)$, lead nitrate $\left(\mathrm{Pb}\left(\mathrm{NO}_{3}\right)_{2}\right)$, nano- $\mathrm{TiO}_{2}$ (P25 grade), methylene blue, malachite green, methyl violet, basic fuchsin, and rhodamine B were all of the analytical reagent grade and purchased from Macklin Reagent (Shanghai, China) without further purification.

\subsection{Hydrothermal Treatment of WRN}

A total of $100 \mathrm{~g}$ of WRN was ground to a smooth paste in a mortar and then mixed with $200 \mathrm{~g}$ deionized water. The resulted mixture was transferred to a $500 \mathrm{~mL}$ sealed Teflon-lined autoclave (Kemi Instrument, Anhui, China) and then heated at $200{ }^{\circ} \mathrm{C}$ for $10 \mathrm{~h}$. A kind of brown solution with black-gray precipitation was obtained. The solid part (HTC powder) can be further processed to obtain activated carbon, while the liquid part (CQDs solution) could be used to obtain $\mathrm{CQDs} / \mathrm{TiO}_{2}$ composite. For $100 \mathrm{~g}$ of WRN, $13.7 \mathrm{~g}$ hydrothermal carbon powder and about $200 \mathrm{~mL}$ CQDs solution could be obtained.

\subsection{Synthesis of AC Based on WRN}

Under optimized conditions, $13.7 \mathrm{~g}$ HTC powder prepared in the previous step was mixed with $27.4 \mathrm{~mL} \mathrm{1 \%} \mathrm{CMC-Na} \mathrm{solution} \mathrm{and} 27.4 \mathrm{~g} \mathrm{KOH}$. The mixture was stirred to form a black plastic paste. It could be formed by die or handcraft to obtain a billet with an appropriate shape. After drying for $24 \mathrm{~h}$ at $60^{\circ} \mathrm{C}$, the billet of $\mathrm{AC}$ was sent to a tubular furnace protected by nitrogen and activated at $800{ }^{\circ} \mathrm{C}$ for $90 \mathrm{~min}$. After activation, the resulting black product was taken out, and the excess alkali in AC was washed off by adding $10 \% \mathrm{HCl}$. The product was then washed to neutral by hot distilled water for four times and dried at $60{ }^{\circ} \mathrm{C}$ for $24 \mathrm{~h}$. In this way, black AC based on WRN was obtained, which could be prepared into powder, particle, or other specific shapes. The conversion rate of AC was $31.6 \%$ based on HTC powder, and $4.3 \mathrm{~g}$ activated carbon could be obtained with $100 \mathrm{~g}$ WRN as raw material. The optimization of the experimental conditions of AC is shown in Table S1 in Supplementary Materials. 


\subsection{Synthesis of CQDs and CQDs/TiO ${ }_{2}$ Composite Based on WRN}

On the other hand, the liquid part (CQDs solution) was filtered and dialyzed in dark for $24 \mathrm{~h}$, resulting in a fluorescent CQDs water solution, which could be directly used for $\mathrm{Fe}^{3+}$ detection (see Figure S1 in Supplementary Materials). However, for the synthesis of CQDs $/ \mathrm{TiO}_{2}$ composite, dialyzation was not a necessary step. After filtration, $200 \mathrm{~mL}$ CQDs solution was directly mixed with $2.5 \mathrm{~g} \mathrm{TiO}_{2}$ powder, and the mixture was stirred at room temperature for $30 \mathrm{~min}$ to obtain a uniform suspension; then the suspension was transferred to an oven and kept at $85{ }^{\circ} \mathrm{C}$ for $3 \mathrm{~h}$. The CQDs $/ \mathrm{TiO}_{2}$ composite was centrifuged, washed with distilled water for three times, and finally dried overnight at $60{ }^{\circ} \mathrm{C}$ in a vacuum environment, which gave a dark brown $\mathrm{CQDs} / \mathrm{TiO}_{2}$ composite with a carbon content of $15.24 \%$. Thus, $2.9 \mathrm{~g}$ CQDs $/ \mathrm{TiO}_{2}$ composite could be obtained with $100 \mathrm{~g}$ WRN as raw material. The optimization of the experimental conditions of $\mathrm{CQDs} / \mathrm{TiO}_{2}$ composite is shown in Table S2 in Supplementary Materials.

\subsection{General Characterization}

The infrared (IR) spectra of the resulting products were recorded as $\mathrm{KBr}$ pellets at a range of $400-4000 \mathrm{~cm}^{-1}$ on a Nicolet 5700 FT-IR spectrometer (Thermofisher, Waltham, MA, USA) with a spectral resolution of $4.00 \mathrm{~cm}^{-1}$. The powder X-ray diffraction (PXRD) patterns were obtained with an X 'pert PRO X-ray diffractometer (Panalytical, Malvern, Worcestershire, UK) with $\mathrm{Cu}$ Ka radiation $(\lambda=0.15418 \AA)$ at $40 \mathrm{kV}$ and $40 \mathrm{~mA}$ and a scan speed of $5^{\circ} \mathrm{min}^{-1}(2 \theta)$. The scanning electron microscope (SEM) images and energy-dispersive $x$-ray (EDX) spectra of AC were obtained by using an S-4800 field emission scanning electron microscope (Hitachi, Chiyoda, Tokyo, Japan) with an accelerating voltage of $20 \mathrm{kV}$. The morphology of CQDs and $\mathrm{CQDs} / \mathrm{TiO}_{2}$ composite were characterized by using JEM-2100F field emission transmission electron microscope (TEM, JEOL, Akishima, Tokyo, Japan) with an accelerating voltage of $200 \mathrm{kV}$. The photoluminescence spectra of pure $\mathrm{TiO}_{2}$ and $\mathrm{CQDs} / \mathrm{TiO}_{2}$ composite were examined with a Cary Eclipse fluorescence spectrophotometer (Varian, Palo Alto, CA, USA) with a xenon lamp as the excitation source in the range of 350 to $650 \mathrm{~nm}$ and an excitation wavelength of $325 \mathrm{~nm}$. The BET-specific surface tests of resulted in AC and other control samples were characterized by using a TriStar II 3020 surface area analyzer (Micromeritics, Atlanta, GA, USA) under a nitrogen atmosphere with an initial temperature of $150{ }^{\circ} \mathrm{C}$ and a heating rate of $10^{\circ} \mathrm{C} / \mathrm{s}$. The X-ray photoelectron spectroscopy (XPS) of $\mathrm{AC}$ and $\mathrm{CQDs} / \mathrm{TiO}_{2}$ composite were carried out with an ESCALAB 250Xi X-ray photoelectron spectrometer (Thermofisher, Waltham, MA, USA) with an Al K $\alpha$ $\mathrm{x}$-ray as the stimulated source. The UV-VIS absorption spectra of $\mathrm{CQDs} / \mathrm{TiO}_{2}$ composite were measured by an UV3100 UV-VIS-NIR spectrophotometer (Shimadzu, Chiyoda, Tokyo, Japan) in diffuse reflection mode, using $\mathrm{BaSO}_{4}$ as reference. The electrochemical properties for pure $\mathrm{TiO}_{2}$ and $\mathrm{CQDs} / \mathrm{TiO}_{2}$ composite were investigated in a three-electrode system with a platinum network counter electrode and an $\mathrm{Ag} / \mathrm{AgCl}$ (saturated $\mathrm{KCl}$ ) reference electrode, using a concentration of $0.1 \mathrm{M} \mathrm{Na}_{2} \mathrm{SO}_{4}$ aqueous electrolyte at $25^{\circ} \mathrm{C}$. The transient photocurrent response was performed on an electrochemical analyzer using $0.5 \mathrm{~V}$ bias voltage under light irradiation with a $300 \mathrm{~W}$ Xe lamp as the light source. The radical production abilities of pure $\mathrm{TiO}_{2}$ and $\mathrm{CQDs} / \mathrm{TiO}_{2}$ composite were investigated by electron paramagnetic resonance (EPR) with a EMXplus X-band electron paramagnetic resonance spectrometer (Bruker, Karlsruhe, Baden-Württemberg, Germany) using dimethyl pyridine $\mathrm{N}$-oxide (DMPO) as spin trapping agent. The elemental analysis data $(\mathrm{C}, \mathrm{H}, \mathrm{N})$ of $\mathrm{AC}$ and other control samples were obtained with a 240B elemental analyzer (PerkinElmer, Wellesley, MA, USA). The determination of the points of zero charge (PZC) of the resulted samples were carried out as follows [45]: $10 \mathrm{~mL}$ of $0.01 \mathrm{M} \mathrm{NaCl}$ solution was placed in a closed centrifugal tube. The $\mathrm{pH}$ was adjusted to a value between 2 and 11 by adding $\mathrm{HCl}$ or $\mathrm{NaOH}$ solutions. Then, $0.05 \mathrm{~g}$ sample was added, and the final $\mathrm{pH}$ was measured after $10 \mathrm{~h}$ under agitation at a sample. The point of zero charges (PZC) was obtained from the intersection of the $\mathrm{pH}_{\text {final }}$ vs. $\mathrm{pH}_{\text {initial }}$ curve of the test sample and that of the blank sample. 


\subsection{Measurement of Adsorption Performance of AC Based on WRN}

$\mathrm{Pb}(\mathrm{II})$ and $\mathrm{Cr}(\mathrm{VI})$ were used to test the adsorption performance of obtained AC to a heavy metal element. Before the experiment, both $\mathrm{Pb}(\mathrm{II})$ and $\mathrm{Cr}(\mathrm{VI})$ were prepared as aqueous solutions with $\mathrm{Pb}\left(\mathrm{NO}_{3}\right)_{2}$ and $\mathrm{K}_{2} \mathrm{Cr}_{2} \mathrm{O}_{7}$ as element sources, whose $\mathrm{pH}$ were both adjusted to 5 . Then, the heavy metal solution was mixed with $\mathrm{AC}$ with an adsorbent dosage of $7 \mathrm{~g} \cdot \mathrm{L}^{-1}$ in a crystallizing dish with continuous magnetic stirring at $25^{\circ} \mathrm{C}$. After absorption, the resulting solution was centrifugated, and the concentration of $\mathrm{Cr}(\mathrm{VI})$ or $\mathrm{Pb}$ (II) was tested with diphenylcarbazide spectrophotometry or dithizone spectrophotometry, respectively. The adsorption capacity of $\mathrm{AC}$ to $\mathrm{Cr}(\mathrm{VI})$ or $\mathrm{Pb}(\mathrm{II})$ was calculated according the spectrophotometry results by the following equation:

$$
q_{e}=\frac{\left(C_{0}-C_{e}\right)}{A D}
$$

Herein, $q_{e}$ is the equilibrium adsorption capacity of adsorbent in $\mathrm{mmol} \cdot \mathrm{g}^{-1} ; C_{0}$ is the initial concentration of the heavy metal ions in $\mathrm{mg} \cdot \mathrm{L}^{-1} ; \mathrm{C}_{e}$ is the equilibrium concentration of the heavy metal ions after adsorption in $\mathrm{mg} \cdot \mathrm{L}^{-1} ; A$ is the atomic weight of heavy metal in $\mathrm{g} / \mathrm{mol}$, and $D$ is the adsorbent dosage in $\mathrm{g} \cdot \mathrm{L}^{-1}$.

The adsorption equilibrium was established within $12 \mathrm{~h}$ for both $\mathrm{Cr}(\mathrm{VI})$ or $\mathrm{Pb}$ (II) adsorption, with the initial concentration of heavy metal element ranging from $20-100 \mathrm{mg} \cdot \mathrm{L}^{-1}$.

The Langmuir and Freundlich adsorption isotherms were applied to describe the adsorption of $\mathrm{AC}$ to $\mathrm{Cr}(\mathrm{VI})$ or $\mathrm{Pb}(\mathrm{II})$ at room temperature [46]. The Langmuir equations are as follows:

$$
q_{e}=\frac{q_{m} b C_{e}}{1+b C_{e}} \text { (nonlinear form) or } \frac{C_{e}}{q_{e}}=\frac{1}{q_{m}^{b}}+\frac{1}{q_{m}} C_{e} \text { (linear form) }
$$

where $q_{m}$ is the maximum amount of heavy metal uptake in $\mathrm{mmol} \cdot \mathrm{g}^{-1} ; b$ is the constant that refers to the bonding energy of adsorption related to free energy and net enthalpy in $\mathrm{L} \cdot \mathrm{mg}^{-1}$.

The Freundlich isotherm is given as:

$$
\left.q_{e}=K_{f} C_{e}^{1 / n} \text { (nonlinear form }\right) \text { or } \log q_{e}=\log K_{f}+\frac{1}{n} \log C_{e}(\text { linear form })
$$

where $K_{f}$ is the constant related to the adsorption capacity of the adsorbent in $\mathrm{mmol} \cdot \mathrm{g}^{-1}$, and $1 / n$ is the intensity of the adsorption constant.

The regression analysis was carried out by OriginPro software (OriginPro 2019, Originlab, Northampton, MA, USA) in order to predict the parameters.

The adsorption dynamics was tested with an initial concentration of $25 \mathrm{mg} / \mathrm{L}$ for both $\mathrm{Cr}(\mathrm{VI})$ or $\mathrm{Pb}$ (II) adsorption with a different adsorption time ranged from 10 to $120 \mathrm{~min}$, and the results were fitted by pseudo-first-order or pseudo-second-order mode [47]. The pseudo-first-order equation was used as:

$$
\log \left(q_{e}-q_{t}\right)=\log q_{e}-\frac{K_{1}}{2.303} t
$$

where $q_{e}$ and $q_{t}$ are the heavy metal uptake at equilibrium and time $t$, respectively, and $K_{1}$ is the constant of first-order adsorption in $\min ^{-1}$.

The pseudo-second-order equation is given as:

$$
\frac{t}{q_{t}}=\frac{1}{K_{2} q_{e}^{2}}+\frac{t}{q_{e}}
$$

where $K_{2}$ is the rate constant of second-order adsorption in $\mathrm{g} \mathrm{mmol}^{-1} \mathrm{~min}^{-1}$.

The regression analysis was also carried out by OriginPro software to predict the parameters. 


\subsection{Measurement of Photocatalytic Performance of $\mathrm{CQDs} / \mathrm{TiO} \mathrm{O}_{2}$ Composite Based on WRN}

Photo-catalytic performance was tested by the photocatalytic degradation of dyes under visible light. First, a $50 \mathrm{~mL}$ dye solution with a concentration of $20 \mathrm{mg} / \mathrm{L}$ and $0.2 \mathrm{~g} \mathrm{CQDs} / \mathrm{TiO}_{2}$ composite was mixed in a crystallization dish with magnetic stirring and then placed under a $20 \mathrm{~W} 405 \mathrm{~nm}$ purple light (or xenon lamp) with an illuminance of $8 \times 10^{4}$ LUX. Such samples were prepared for several repeat experiments. After a certain time, one of the crystallizing dishes was taken out. The resulted solution was centrifugated, and its dye concentration was tested by UV-VIS spectrophotometry. The photocatalytic rate of CQDs/ $\mathrm{TiO}_{2}$ composite was calculated according to the spectrophotometry results.

The photocatalytic degradation of organic pollutants at the liquid-solid interface can be described by the Langmuir Hinshelwood model [48], in which the integral form is

$$
t=\left(\frac{1}{K_{r} K}\right) \ln \left(\frac{C_{0}}{C}\right)+\frac{C_{0}-C}{K_{r}}
$$

where $t$ refers to the irradiation time; $C_{0}$ is the initial concentration of organic dye, and $C$ is the concentration of pollutant at time $t ; K$ is the equilibrium constant for the organic dye adsorption on the catalyst, and $K_{r}$ reflects the limiting rate of the reaction at the maximum coverage under the given conditions.

At a low initial concentration of organic dye, the second term in Equation (6) becomes insignificant, and hence, it can be neglected. Thus, the kinetic fitting of photocatalytic degradation in this paper used the following equation:

$$
\ln \left(\frac{C_{0}}{C}\right)=K_{r} K t=K_{a p p} t
$$

where $K_{a p p}$ is the apparent constant in $\min ^{-1}$ used as the basic kinetic parameter for different photocatalysts.

\section{Result and Discussion}

\subsection{Structural Characterization of AC Based on WRN}

As shown in Table 1, the HTC powder was a partially carbonized intermediate product with about $51 \mathrm{wt} \%$ carbon content. Due to the high starch content of WRN, the majority of the particles of HTC showed a spherical morphology with a smooth surface (Figure S2 in Supplementary Materials). Thus, the HTC displayed a very low surface area and could not be used for heavy metal adsorption directly. However, the HTC could generate thermal decomposition over $400{ }^{\circ} \mathrm{C}$ (Figure S3 in Supplementary Materials). Thus, by activation at $800{ }^{\circ} \mathrm{C}$ with $\mathrm{KOH}, \mathrm{AC}$ for heavy metal adsorption could be obtained. Compared with HTC, the resulting AC based on WRN showed a higher graphitization degree, in which the broad peaks at about 25 and $43^{\circ}$ represented the (002) and (100) crystal planes of graphite, respectively. The AC based on WRN showed the morphology of porous sphere with a dimension of 10-20 $\mu \mathrm{m}$ (see Figure $2 \mathrm{~b}$ ), which displayed a high BET-specific surface area of $1250.4 \mathrm{~m}^{2} \cdot \mathrm{g}^{-1}$ and an average pore size of $2.48 \mathrm{~nm}$, as well as a high adsorption value to methylene blue of $321 \mathrm{mg} \cdot \mathrm{g}^{-1}$ and an iodine value of $961 \mathrm{mg} \cdot \mathrm{g}^{-1}$. In addition, the AC net exhibited a type II isotherm in nitrogen adsorption and an $\mathrm{H}_{2} / \mathrm{H}_{4}$ hysteresis loop, which was a complex product composed of microporous and mesoporous structures (Table 1 , Figure $2 \mathrm{c}, \mathrm{d}$ ). The IR spectrum revealed that there was a hydroxyl group in the surface of the resultant AC, in which the vibrations of $\sigma_{\mathrm{O}-\mathrm{H}}$ and $\sigma_{\mathrm{C}-\mathrm{O}}$ were located at $3441 \mathrm{~cm}^{-1}$ and $1039 \mathrm{~cm}^{-1}$, respectively, while the stretch of $\mathrm{C}=\mathrm{C}$ in aromatic rings was located at $1636 \mathrm{~cm}^{-1}$ (Figure 2e). The XPS spectra showed the existence of $\mathrm{C}$ and $\mathrm{O}$ elements in the resulting $\mathrm{AC}$ (see Figure $2 \mathrm{f}$ ). In the high-resolution spectrum of $\mathrm{C} 1 \mathrm{~s}$, the characteristic peak at $284.28 \mathrm{eV}, 286.01 \mathrm{eV}$, and $288.37 \mathrm{eV}$ could be attributed to $\mathrm{C}-\mathrm{C}$ bond, $\mathrm{C}-\mathrm{O}$ bond, and $\mathrm{C}=\mathrm{C}$ bond, respectively (see Figure $2 \mathrm{~g}$ ). The high-resolution spectrum of $\mathrm{O} 1 \mathrm{~s}$ showed the existence of $\mathrm{C}-\mathrm{O}$ and $\mathrm{O}-\mathrm{H}$ bonds, whose characteristic signals were located at $531.49 \mathrm{eV}$ and $532.76 \mathrm{eV}$, respectively (see Figure $2 \mathrm{~h}$ and Table 2). 
Table 1. Ultimate analyses and characteristic of $\mathrm{AC}, \mathrm{HTC}$, as well as $\mathrm{AC}$ after $\mathrm{Pb}(\mathrm{II})$ and $\mathrm{Cr}(\mathrm{VI})$ adsorption.

\begin{tabular}{|c|c|c|c|c|c|c|c|}
\hline \multirow{2}{*}{ Product } & \multicolumn{3}{|c|}{ Ultimate Analysis (wt. \%) } & \multirow{2}{*}{$\begin{array}{l}\text { BET Surface } \\
\text { Area }\left(\mathrm{m}^{2} \cdot \mathrm{g}^{-1}\right)\end{array}$} & \multirow{2}{*}{$\begin{array}{l}\text { Micropore Volume } \\
\qquad\left(\mathrm{cm}^{3} \cdot \mathrm{g}^{-1}\right)\end{array}$} & \multirow{2}{*}{$\begin{array}{l}\text { Average Pore } \\
\text { Width }(\mathrm{nm})\end{array}$} & \multirow{2}{*}{$\begin{array}{l}\text { Point of Zero } \\
\text { Charge (PZC) }\end{array}$} \\
\hline & $\mathrm{C}$ & $\mathbf{H}$ & $\mathbf{N}$ & & & & \\
\hline $\mathrm{AC}$ & 84.17 & 1.21 & 1.30 & 1250.35 & 0.4053 & 2.4773 & 5.83 \\
\hline HTC & 51.03 & 4.20 & 1.58 & 0.18 & 0.0004 & - & 5.04 \\
\hline $\mathrm{AC}-\mathrm{Cr}^{\mathrm{a}}$ & 82.95 & 1.30 & 1.28 & 793.12 & 0.3136 & 2.3959 & 5.97 \\
\hline $\mathrm{AC}-\mathrm{Pb}{ }^{b}$ & 80.99 & 1.26 & 1.84 & 803.25 & 0.2983 & 2.3647 & 5.64 \\
\hline
\end{tabular}

a The AC sample after $\mathrm{Cr}(\mathrm{VI})$ adsorption in $100 \mathrm{mg} / \mathrm{L} \mathrm{Cr}(\mathrm{VI})$ solution with an adsorbent dosage of $7 \mathrm{~g} \cdot \mathrm{L}^{-1}$ for $12 \mathrm{~h}$

$\mathrm{b}$ The AC sample after $\mathrm{Pb}(\mathrm{II})$ adsorption in $100 \mathrm{mg} / \mathrm{L} \mathrm{Pb}(\mathrm{II})$ solution with an adsorbent dosage of $7 \mathrm{~g} \cdot \mathrm{L}^{-1}$ for $12 \mathrm{~h}$.

(a)

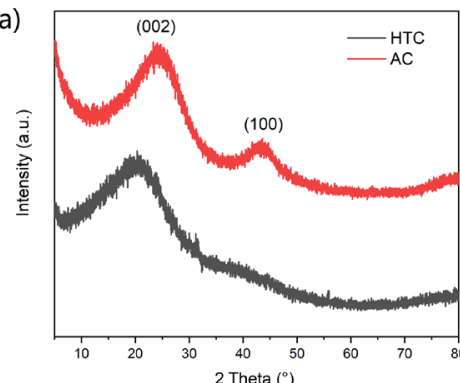

(c)

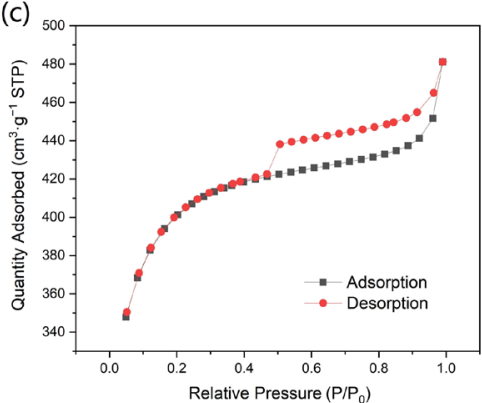

(e)

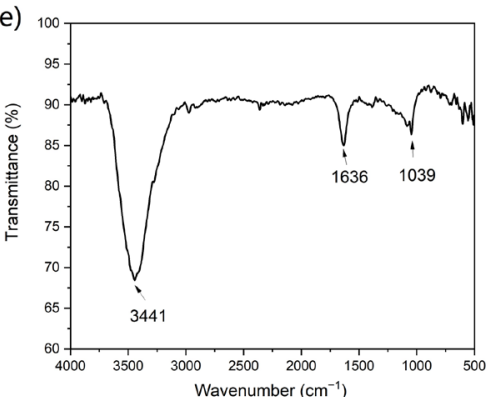

(g)

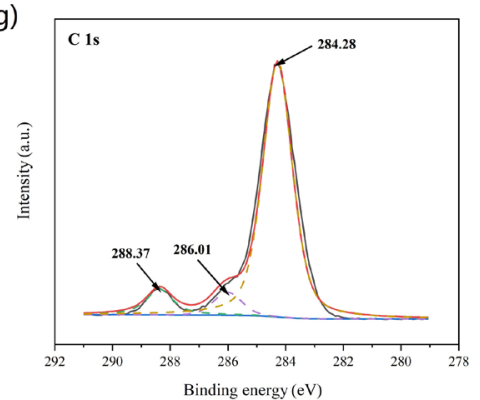

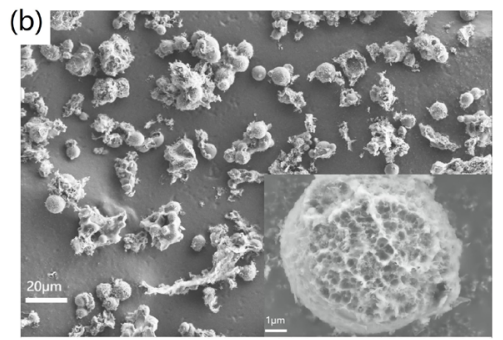

(d)

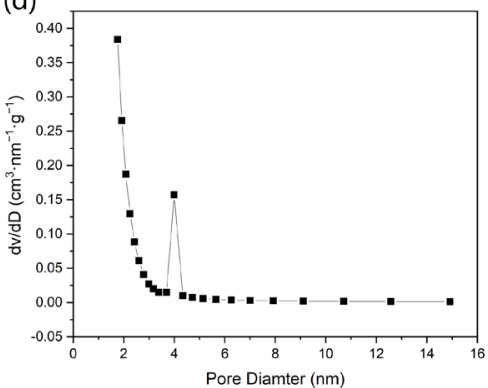

(f)

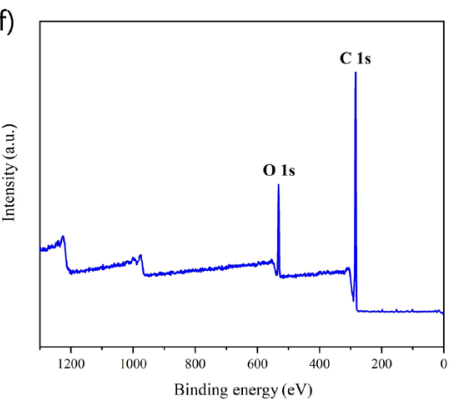

(h)

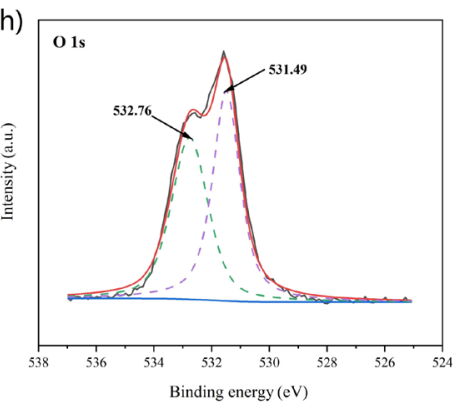

Figure 2. (a-c): The PXRD pattern (a), SEM image (b), nitrogen adsorption/desorption isotherms (c), pore-size-distribution curves (d), and IR spectrum (e) of AC based on WRN; (f-h): The full XPS (f), $\mathrm{C} 1 \mathrm{~s}(\mathbf{g})$, and $\mathrm{O} 1 \mathrm{~s}(\mathbf{h})$ high-resolution spectra of AC based on WRN. 
Table 2. The assignment of the XPS peaks of AC based on WRN.

\begin{tabular}{cccc}
\hline Element & Peak (eV) & Surface Group & Assignment \\
\hline \multirow{2}{*}{ C1s } & 284.28 & $\mathrm{C}$ & $\begin{array}{c}\text { Graphitic carbon } \\
\end{array}$ \\
& 286.01 & $\mathrm{C}-\mathrm{O}$ & $\begin{array}{c}\text { Phenolic, alcoholic or etheric structure } \\
\pi \text {-electrons in aromatic ring }\end{array}$ \\
\hline \multirow{2}{*}{ O1s } & 288.37 & $\mathrm{C}=\mathrm{C}$ & $\begin{array}{c}\text { Oxygen singly bonded to carbon in } \\
\text { aromatic rings }\end{array}$ \\
& 531.49 & $\mathrm{C}-\mathrm{O}$ & Hydroxyl group \\
\hline
\end{tabular}

\subsection{Adsorption Performance to Heavy Metals of AC Based on WRN}

Figure $3 a$, d shows the experimental adsorption isotherms according to the equilibrium $\mathrm{Pb}$ (II) and $\mathrm{Cr}(\mathrm{VI})$ concentrations at room temperature, respectively. To gain some insight into the adsorption, the batch adsorption process was fitted using the two classical empirical models of Langmuir and Freundlich. Regression analysis of the linearized isotherms of Langmuir $\left(C_{e} / q_{e}\right.$ versus $\left.C_{e}\right)$ and Freundlich $\left(\log q_{e}\right.$ versus $\left.\log C_{e}\right)$, using the slope and the intercept, gave the sorption constants $\left(q_{m}, b\right.$ and $\left.K_{f}, 1 / n\right)$ and correlation coefficients $\left(\mathrm{R}^{2}\right)$. The linear forms of the Langmuir and Freundlich equations are shown in Figure $3 b, c, e, f$. The $q_{m}, b, K_{f}, 1 / n$ values and the linear regression correlations for Langmuir and Freundlich modes are listed in Table 3. It could be observed that the AC based on WRN displayed good adsorption performance on heavy metal ions. The adsorption of $\mathrm{Pb}(\mathrm{II})$ and $\mathrm{Cr}(\mathrm{VI})$ on the AC could follow both Freundlich and Langmuir type adsorption isotherms. However, based on the regression coefficients, the Langmuir isotherm fitted the experimental data slightly better than the Freundlich model, which indicates that there was a homogenous distribution of active sites on the surface of AC. Based on Langmuir isotherm, the AC based on WRN showed the highest metal uptake of $0.0583 \mathrm{mmol} \cdot \mathrm{g}^{-1}$ (or $12.08 \mathrm{mg} \cdot \mathrm{g}^{-1}$ ) for $\mathrm{Pb}$ (II) and $0.180 \mathrm{mmol} \cdot \mathrm{g}^{-1}$ (or $9.36 \mathrm{mg} \cdot \mathrm{g}^{-1}$ ) for $\mathrm{Cr}(\mathrm{VI})$ (come from $\mathrm{q}_{\mathrm{m}}$ data in Table 3). Compared with other AC adsorbents for the elimination of heavy metal ions (Table 4), the AC based on WRN show similar $\mathrm{Cr}(\mathrm{VI})$ adsorption capacity to some low-cost $\mathrm{AC}$ adsorbents produced from coconut shell [21] or peanut shell [23], as well as similar $\mathrm{Pb}$ (II) adsorption capacity to the hazelnut-husk-based AC [25]. Combined with the low cost of WRN, the AC based on WRN had potential application in the treatment of heavy metal water pollution.

Table 3. Adsorption parameters of the Langmuir and Freundlich isotherms at room temperature for the adsorption of $\mathrm{Pb}(\mathrm{II})$ and $\mathrm{Cr}(\mathrm{VI})$.

\begin{tabular}{|c|c|c|c|c|c|c|}
\hline \multirow{2}{*}{$\begin{array}{l}\text { Heavy Metal } \\
\text { Ion }\end{array}$} & \multicolumn{3}{|c|}{ Langmuir } & \multicolumn{3}{|c|}{ Freundlich } \\
\hline & $q_{m}\left(\mathrm{mmol} \cdot \mathrm{g}^{-1}\right)$ & $b\left(\mathrm{~L} \cdot \mathrm{mg}^{-1}\right)$ & $\mathbf{R}^{2}$ & $K_{f}\left(\mathrm{mmol} \cdot \mathrm{g}^{-1}\right)$ & $1 / n$ & $\mathbf{R}^{2}$ \\
\hline $\mathrm{Pb}(\mathrm{II})$ & $0.0583 \pm 0.0016$ & $0.8614 \pm 0.0049$ & 0.9954 & $0.0294 \pm 0.0006$ & $0.2687 \pm 0.0127$ & 0.9867 \\
\hline $\mathrm{Cr}(\mathrm{VI})$ & $0.1800 \pm 0.0048$ & $1.0415 \pm 0.0088$ & 0.9956 & $0.0134 \pm 0.0014$ & $0.2085 \pm 0.0085$ & 0.9899 \\
\hline
\end{tabular}

Table 4. Adsorption capacity of $\mathrm{Pb}(\mathrm{II})$ and $\mathrm{Cr}(\mathrm{VI})$ by $\mathrm{AC}$ with different low cost raw materials.

\begin{tabular}{|c|c|c|c|c|c|}
\hline Heavy Metal Ion & Raw Materials & $\begin{array}{c}\text { Adsorbent Dosage } \\
\left(\mathrm{g} \cdot \mathrm{L}^{-1}\right)\end{array}$ & $\mathrm{pH}$ & $\begin{array}{c}\text { Adsorption Capacity } \\
\left(\mathrm{mg} \cdot \mathrm{g}^{-1}\right)\end{array}$ & Reference \\
\hline \multirow[t]{6}{*}{$\mathrm{Pb}(\mathrm{II})$} & Polygonum orientale Linn. & 0.6 & 5 & 98.39 & [28] \\
\hline & Pecan shell & $0.5-10$ & 4.8 & 64.20 & [22] \\
\hline & Date pit & 4.0 & 5.2 & 30.70 & [24] \\
\hline & Coconut shell & 2 & 5 & 21.88 & [20] \\
\hline & Hazelnut husk & 12 & 5.7 & 13.05 & [25] \\
\hline & Waste rice noodles (WRN) & 7 & 5 & 12.08 & This work \\
\hline \multirow{6}{*}{$\mathrm{Cr}(\mathrm{VI})$} & Paper mill sludge & $1.5-7$ & 4 & 23.18 & [27] \\
\hline & Peanut shell & 1 & 2 & 8.31 & [23] \\
\hline & Eichhornia crassipes root & 7 & 4.5 & 36.34 & [29] \\
\hline & Coconut shell & 2 & 4 & 10.88 & [21] \\
\hline & Sagowaste & 2 & 2 & 5.78 & [26] \\
\hline & Waste rice noodles (WRN) & 7 & 5 & 9.36 & This work \\
\hline
\end{tabular}


(a)

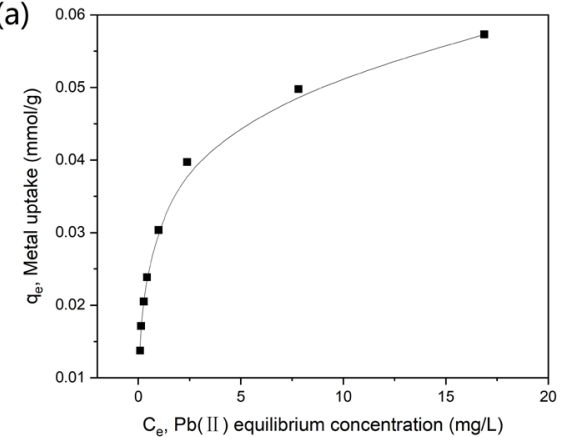

(c)

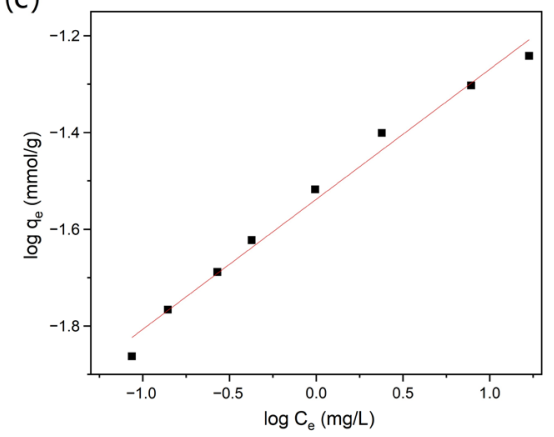

(e)

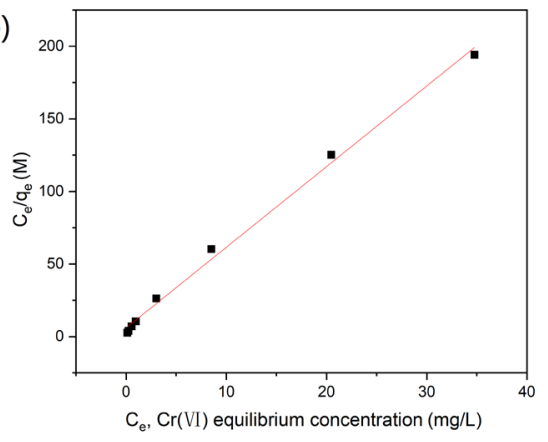

(b)

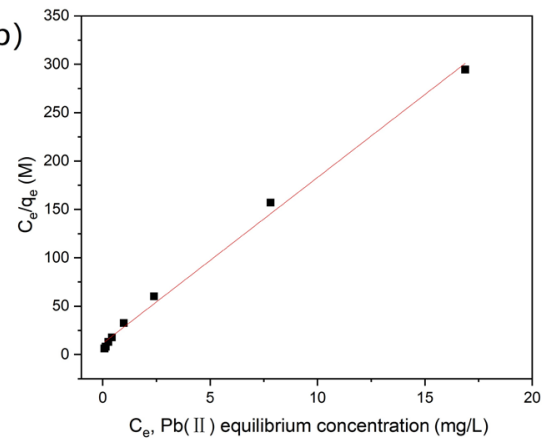

(d)
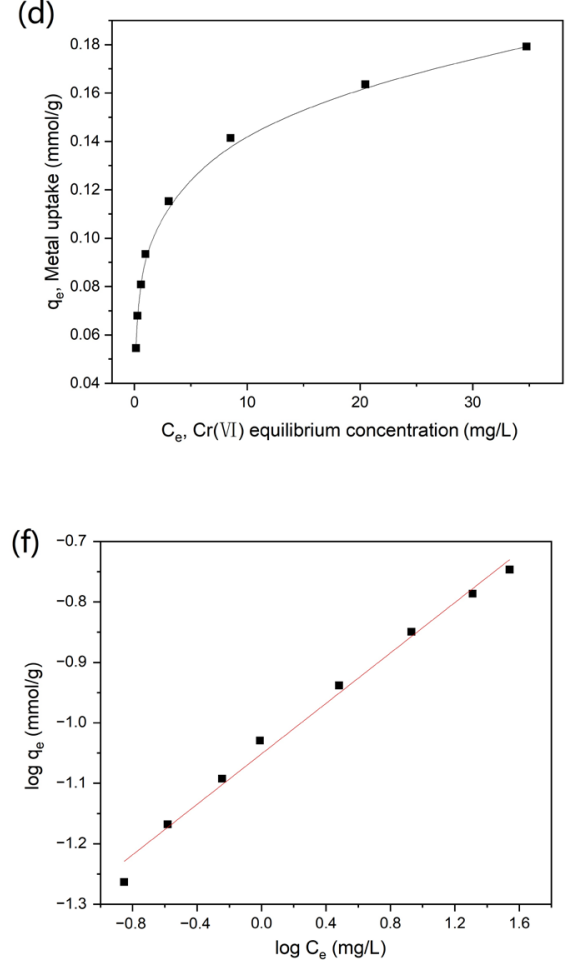

Figure 3. (a-c): The adsorption isotherm of resulted in $\mathrm{AC}$ to $\mathrm{Pb}(\mathrm{II})$ by equilibrium concentration (a), Langmuir equation (linear form, (b)) and Freundlich equation (linear form, (c)); (d-f): the adsorption isotherm of resulted from $\mathrm{AC}$ to $\mathrm{Cr}(\mathrm{VI})$ by equilibrium concentration (d), Langmuir equation (linear form, (e)), and Freundlich equation (linear form, (f)).

The AC showed a decreased BET surface areas after $\mathrm{Cr}(\mathrm{VI})$ and $\mathrm{Pb}(\mathrm{II})$ adsorption but maintained a similar type of isotherm and pore size distribution (see Table 1 and Figure S4 in Supplementary Materials). The slight reduction of carbon content from the ultimate analysis could be attributed to the incidental adsorption of heavy metal elements and other counter ions. As shown in Figure $4 a, b$, after the adsorption of heavy metals, the AC based on WRN could maintain its porous spherical structure, and heavy metal elements generated a homogenous distribution. The PXRD patterns of AC before and after $\mathrm{Cr}(\mathrm{VI})$ and $\mathrm{Pb}(\mathrm{II})$ adsorption revealed that the angle of graphite diffraction peaks of AC moved to lower angles after heavy metal adsorption (Figure 4c). Moreover, from the IR spectra of AC before and after heavy metal adsorption, the $\mathrm{C}-\mathrm{O}$ vibration peak located at $1039 \mathrm{~cm}^{-1}$ red shift and the vibration peak of $\mathrm{Pb}-\mathrm{O}$ and $\mathrm{Cr}-\mathrm{O}$ were observed at 660 and $629 \mathrm{~cm}^{-1}$, respectively, which indicated that chemical action of $\mathrm{AC}$ and heavy metal ions occurred in the adsorption process (Figure $4 \mathrm{~d}$ ). 

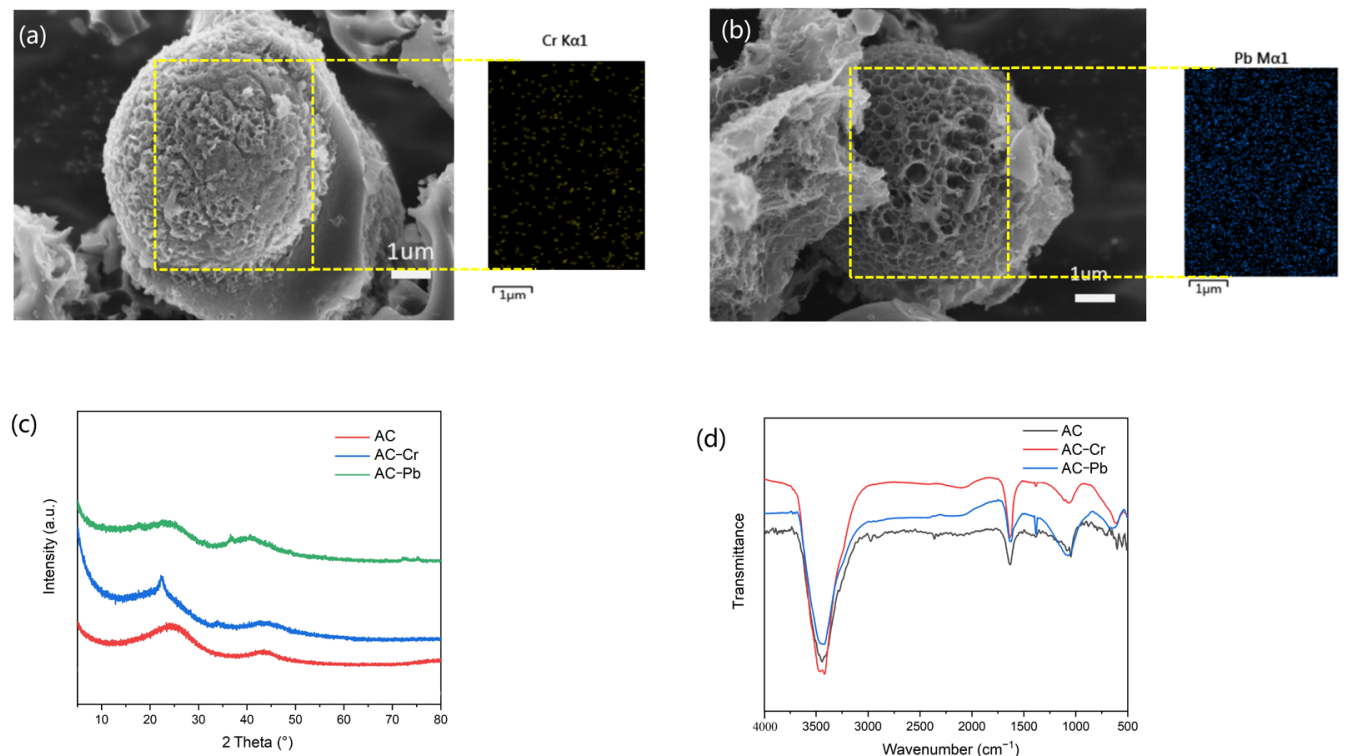

Figure 4. $(\mathbf{a}, \mathbf{b})$ The SEM image and heavy metal distribution image of the AC sample after $\mathrm{Cr}(\mathrm{VI})(\mathbf{a})$ and $\mathrm{Pb}(\mathrm{II})(\mathbf{b})$ adsorption; (c) the PXRD patterns of $\mathrm{AC}$ before and after $\mathrm{Cr}(\mathrm{VI})$ and $\mathrm{Pb}$ (II) adsorption; (d) the IR spectra of $\mathrm{AC}$ before and after $\mathrm{Cr}(\mathrm{VI})$ and $\mathrm{Pb}$ (II) adsorption. The adsorption samples were obtained in $100 \mathrm{mg} \cdot \mathrm{L}^{-1}$ heavy metal solution with an adsorbent dosage of $7 \mathrm{~g} \cdot \mathrm{L}^{-1}$ for $12 \mathrm{~h}$.

The AC based on WRN also shows good adsorption speed to heavy metal ions. As shown in Figure 5a,d, the AC could approach the adsorption equilibrium of both $\mathrm{Pb}(\mathrm{II})$ and $\mathrm{Cr}(\mathrm{VI})$ after $90 \mathrm{~min}$ adsorption in $25 \mathrm{mg} \cdot \mathrm{L}^{-1}$ heavy metal solution. Furthermore, the pseudo-first-order and the pseudo-second-order kinetics models were employed to test of the experimental data of adsorption speed. The $q_{e 1}, q_{e 2}, K_{1}, K_{2}$ values were determined experimentally from the slope and intercept of straight-line adsorption kinetic plot. The linear forms of the pseudo-first-order and pseudo-second-order kinetic fitting are shown in Figure $5 b, c, e, f$. The values and regression coefficient are presented in Table 5 . It could be observed that the adsorption process of $\mathrm{Pb}(\mathrm{II})$ and $\mathrm{Cr}(\mathrm{VI})$ by $\mathrm{AC}$ both accorded with the pseudo-second-order kinetic model better, which suggested that the heavy metal adsorption process of the AC was controlled by the chemisorption mechanism.

Table 5. The kinetic adsorption parameters were obtained using pseudo-first-order and pseudosecond-order for the adsorption of $\mathrm{Cr}(\mathrm{VI})$ and $\mathrm{Pb}(\mathrm{II})$.

\begin{tabular}{ccccccc}
\hline \multirow{2}{*}{ Heavy Metal Ion } & \multicolumn{3}{c}{ Pseudo-First-Order } & \multicolumn{3}{c}{ Pseudo-Second-Order } \\
\cline { 2 - 7 } & $\boldsymbol{K}_{\mathbf{1}}\left(\mathbf{m i n}^{-\mathbf{1}}\right)$ & $\boldsymbol{q}_{\boldsymbol{e} \mathbf{1}}\left(\mathbf{m} \mathbf{m o l} \cdot \mathbf{g}^{-\mathbf{1}}\right)$ & $\mathbf{R}^{\mathbf{2}}$ & $\begin{array}{c}\boldsymbol{K}_{\mathbf{2}} \\
\mathbf{( g} \cdot \mathbf{m m o l} \cdot \mathbf{m i n}^{-\mathbf{1})}\end{array}$ & $\boldsymbol{q}_{\boldsymbol{e} \mathbf{2}}\left(\mathbf{m m o l} \cdot \mathbf{g}^{-\mathbf{1})}\right.$ & $\mathbf{R}^{\mathbf{2}}$ \\
\hline $\mathrm{Pb}(\mathrm{II})$ & $0.0435 \pm 0.0002$ & $0.0114 \pm 0.0001$ & 0.9832 & $5.1481 \pm 0.0582$ & $0.0188 \pm 0.0003^{\mathrm{a}}$ & 0.9974 \\
$\mathrm{Cr}(\mathrm{VI})$ & $0.0527 \pm 0.0001$ & $0.0488 \pm 0.0005$ & 0.9924 & $2.1421 \pm 0.0138$ & $0.0720 \pm 0.0004^{\mathrm{b}}$ & 0.9997 \\
\hline
\end{tabular}

a The experimental value $\left(q_{e}\right)$ of $\mathrm{Pb}(\mathrm{II})$ was $0.0172 \mathrm{mmol} \cdot \mathrm{g}^{-1}$; b The experimental value $\left(q_{e}\right)$ of $\mathrm{Cr}(\mathrm{VI})$ was $0.0680 \mathrm{mmol} \cdot \mathrm{g}^{-1}$. 

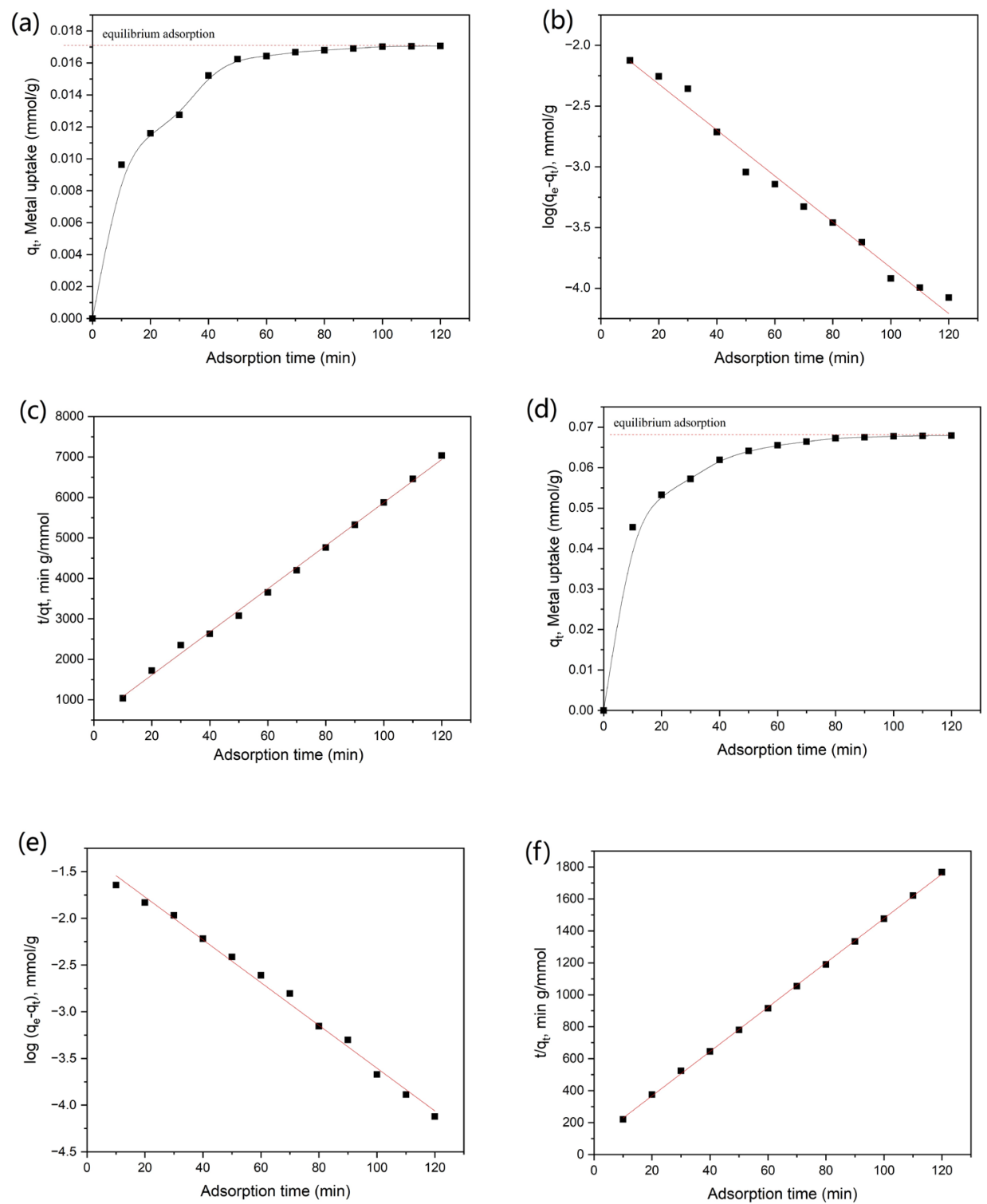

Figure 5. (a-c) Adsorption of $\mathrm{Pb}$ (II) with $\mathrm{AC}$ by contact time (a), pseudo-first-order kinetics (b) and pseudo-second-order (c) kinetics mode; (d-f) adsorption of $\mathrm{Cr}(\mathrm{VI})$ with AC by contact time (d), pseudo-first-order kinetics (e) and pseudo-second-order (f) kinetics mode.

\subsection{Structural Characterization of $\mathrm{CQDs}$ and $\mathrm{CQDs} / \mathrm{TiO}_{2}$ Composite Based on WRN}

As shown in Figure 6a-c, CQDs synthesized by WRN showed an oval or spherical morphology, whose (020) crystal plane with a lattice spacing of about $0.283 \mathrm{~nm}$ could be observed. Its particle size was mainly distributed between $1.5-2.5 \mathrm{~nm}$, which was well dispersed and barely reunited. The IR spectrum indicated that there were carboxyl groups in the CQDs with an absorption peak at $1709 \mathrm{~cm}^{-1}$, which might play an important role in the combination of $\mathrm{TiO}_{2}$. The hydroxyl and alkyl groups also existed in the resulting CQDs. The vibration of the hydroxyl group was located at about $3424 \mathrm{~cm}^{-1}$. The stretch of $\mathrm{C}=\mathrm{C}$ in aromatic rings was located at $1629 \mathrm{~cm}^{-1}$. The absorption peaks of 2926, 1384, and $669 \mathrm{~cm}^{-1}$ could be assigned to the stretching and bending vibration of alkyl groups (see Figure $6 \mathrm{~d}$ ). 


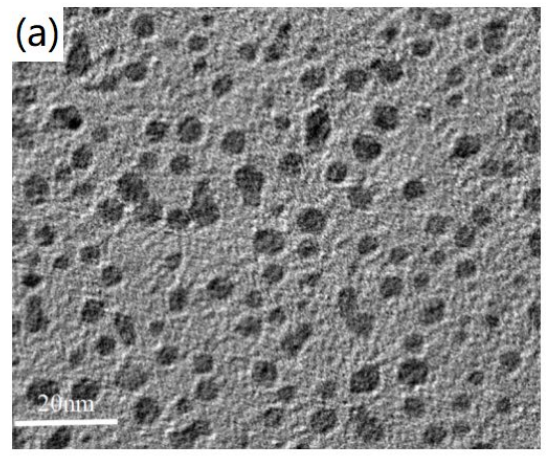

(c)

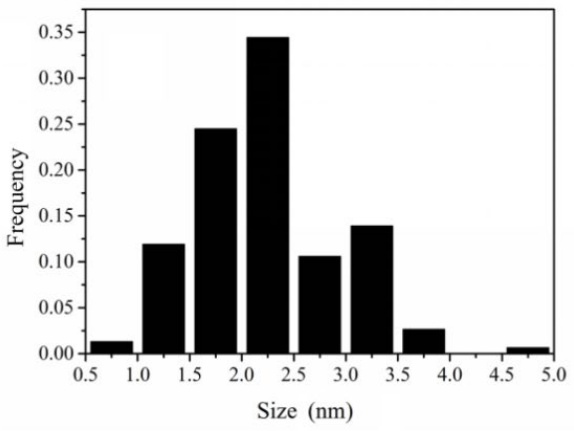

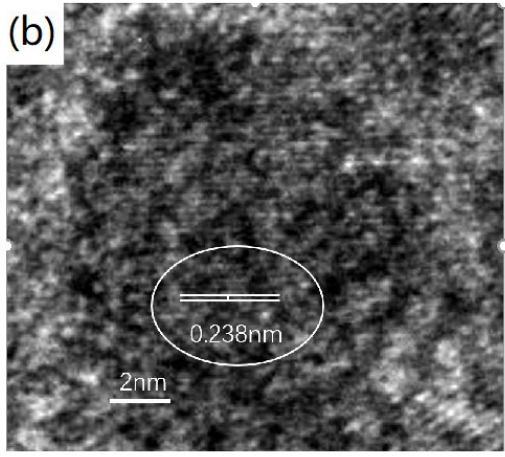

(d)

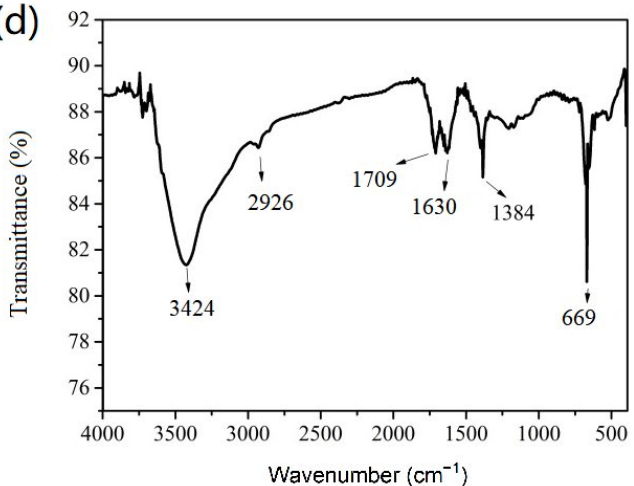

Figure 6. The TEM image (a), HRTEM image (b), particle-size distribution (c), and IR spectrum (d) of CQDs based on WRN.

As shown in Figure 7a, the CQDs $/ \mathrm{TiO}_{2}$ composite presented a nearly square or eggshaped nanostructure with a diameter range of 10-70 nm, and spherical particles of CQDs were evenly dispersed on the surface of $\mathrm{TiO}_{2}$. HRTEM image showed both the lattice interleaving of nano $\mathrm{TiO}_{2}$ and CQDs, in which the lattice stripes with a spacing of $0.149 \mathrm{~nm}$ and $0.114 \mathrm{~nm}$ belonged to (213) and (004) crystal planes of anatase $\mathrm{TiO}_{2}$, respectively, while the crystal plane spacing of $0.169 \mathrm{~nm}$ was highly matched with the (220) plane of rutile $\mathrm{TiO}_{2}$. In addition, a crystal plane with a lattice spacing of about $0.283 \mathrm{~nm}$ could be observed, which corresponded to the (020) crystal plane of CQDs (see Figure 7b). Thus, it was clear that the CQDs and nano $\mathrm{TiO}_{2}$ were successfully combined in the resulting composite. The formation of CQDs $/ \mathrm{TiO}_{2}$ composite was further proved by IR characterization (see Figure 7c). Among them, the stretching vibration of the carboxyl group in original CQDs vanished after combination with $\mathrm{TiO}_{2}$, and the wide absorption band of pure $\mathrm{TiO}_{2}$ below $1000 \mathrm{~cm}^{-1}$ had an obvious red shift and narrowing after combination, which might be due to the reaction between carboxyl group in CQDs and hydroxyl group on the surface of $\mathrm{TiO}_{2}$. The XPS spectra showed the existence of $\mathrm{C}, \mathrm{O}$, and Ti elements in the resulting $\mathrm{CQDs} / \mathrm{TiO}_{2}$ composite (see Figure $7 \mathrm{~d}$ and Table 6). In the high-resolution spectrum of $\mathrm{C}$ $1 \mathrm{~s}$, the characteristic peak at $284.71 \mathrm{eV}$ could be attributed to $\mathrm{C}-\mathrm{C}$ bond in CQDs, while the characteristic signals centered at 285.83 and $289.20 \mathrm{eV}$ were related to the $\mathrm{C}-\mathrm{O}$ bond and $\mathrm{C}=\mathrm{C}$ bond, respectively (See Figure 7e). The high-resolution spectrum of $\mathrm{O} 1 \mathrm{~s}$ showed the existence of $\mathrm{Ti}-\mathrm{O}, \mathrm{C}-\mathrm{O}$, and $\mathrm{O}-\mathrm{H}$ bonds, whose characteristic signals were located at $529.79,531.30$, and $532.64 \mathrm{eV}$, respectively. The characteristic peaks in Ti $2 \mathrm{p}$ spectrum at 458.50 and $464.20 \mathrm{eV}$ belonged to the signals of $\mathrm{Ti}\left(2 \mathrm{p}_{3 / 2}\right)$ and $\mathrm{Ti}\left(2 \mathrm{p}_{1 / 2}\right)$. In addition, due to organic groups in CQDs, the point of zero charge (PZC) value of CQDs $/ \mathrm{TiO}_{2}$ composite (6.77) is higher than that of pure $\mathrm{TiO}_{2}(6.03$, see Figure $7 \mathrm{~h})$ 

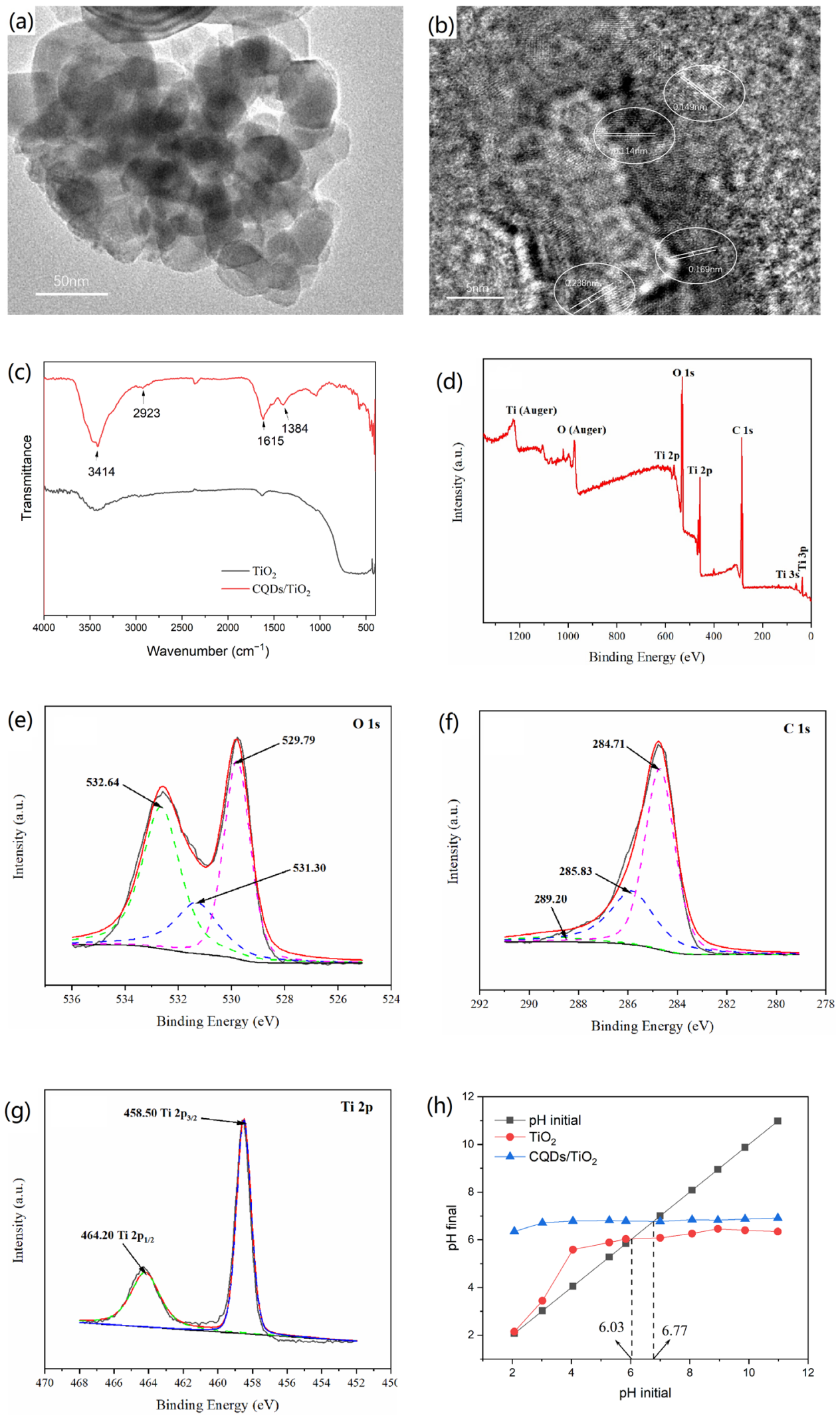

Figure 7. (a,b) The TEM image (a) and HRTEM image (b) of CQDs $/ \mathrm{TiO}_{2}$ composite based on WRN; (c) IR spectra pure $\mathrm{TiO}_{2}$ and $\mathrm{CQDs} / \mathrm{TiO}_{2}$ composite. (d-g): The full XPS (d), O $1 \mathrm{~s}(\mathbf{e}), \mathrm{C} 1 \mathrm{~s}(\mathbf{f})$, and Ti $2 \mathrm{p}(\mathrm{g})$ high-resolution spectra of $\mathrm{CQDs} / \mathrm{TiO}_{2}$ composite based on WRN. (h) PZC of pure $\mathrm{TiO}_{2}$ and $\mathrm{CQDs} / \mathrm{TiO}_{2}$ composite. 
Table 6. The assignment of the XPS peaks of $\mathrm{CQDs} / \mathrm{TiO}_{2}$ composite based on WRN.

\begin{tabular}{cccc}
\hline Element & Peak (eV) & Surface Group & Assignment \\
\hline \multirow{2}{*}{ C 1 s } & 284.71 & $\mathrm{C}$ & $\begin{array}{c}\text { Graphitic carbon } \\
\end{array}$ \\
& 285.83 & $\mathrm{C}-\mathrm{O}$ & $\begin{array}{c}\text { Phenolic, alcoholic or etheric structure } \\
\pi \text {-electrons in aromatic ring }\end{array}$ \\
\hline \multirow{2}{*}{$\mathrm{O} 1 \mathrm{~s}$} & 529.20 & $\mathrm{C}=\mathrm{C}$ & $\begin{array}{c}\text { Oxygen bonded to titanium } \\
\text { Oxygen singly bonded to carbon in } \\
\end{array}$ \\
& 531.30 & $\mathrm{Ti}-\mathrm{O}$ & aromatic rings \\
& 532.64 & $\mathrm{C}-\mathrm{O}$ & Hydroxyl group \\
\hline \multirow{2}{*}{$\mathrm{Ti} 2 \mathrm{p}$} & 458.50 & $\mathrm{O}-\mathrm{H}$ & $\mathrm{Ti}\left(2 \mathrm{p}_{3 / 2}\right)$ \\
& 464.20 & $\mathrm{Ti}$ & $\mathrm{Ti}\left(2 \mathrm{p}_{1 / 2}\right)$ \\
\hline
\end{tabular}

\subsection{Photocatalytic Performance of $\mathrm{CQDs} / \mathrm{TiO}_{2}$ Composite}

The resulting CQDs $/ \mathrm{TiO}_{2}$ composite displayed a high efficient photocatalytic degradation effect to various water-soluble dyes. The methylene blue $[49,50]$ was one of the most common pollutants in dyeing waste water with considerable toxicity. As shown in Figure 8a, this methylene blue was difficult to degrade under $405 \mathrm{~nm}$ visible purple light. After $80 \mathrm{~min}$ of illumination, the degradation rate was only $3.32 \%$. The pure nano $\mathrm{TiO}_{2}$ had a catalytic effect on methylene blue but a complete degradation could not be achieved, with a degradation rate of $3.18 \%$ within $10 \mathrm{~min}$ and $59.85 \%$ within $80 \mathrm{~min}$. By contrast, the CQDs $/ \mathrm{TiO}_{2}$ composite based on WRN had much better photocatalytic performance, whose degradation rate could be as high as $81.84 \%$ within $10 \mathrm{~min}$ and $99.87 \%$ within $80 \mathrm{~min}$. Moreover, the $\mathrm{CQDs} / \mathrm{TiO}_{2}$ composite could be recycled and reused without any appreciable decrease in degradation rate, which could maintain a degradation rate of more than $96.5 \%$ after seven photocatalytic cycles (See Figure $8 \mathrm{~b}$ ). In addition, the degradation rate of CQDs $/ \mathrm{TiO}_{2}$ composite could be affected by the loading dosage of $C Q D_{S}$. For example, the degradation rate of the $\mathrm{CQD}_{\mathrm{S}} / \mathrm{TiO}_{2}$ sample with a carbon content of $4.96 \mathrm{wt} \%\left(\mathrm{CQD}_{\mathrm{S}} / \mathrm{TiO}_{2}-4\right)$ showed a degradation rate of $93.3 \%$ within $80 \mathrm{~min}$, which was slightly lower than other $\mathrm{CQDs} / \mathrm{TiO}_{2}$ composite with higher carbon content (see Figure S7 in Supplementary Materials).

(a)

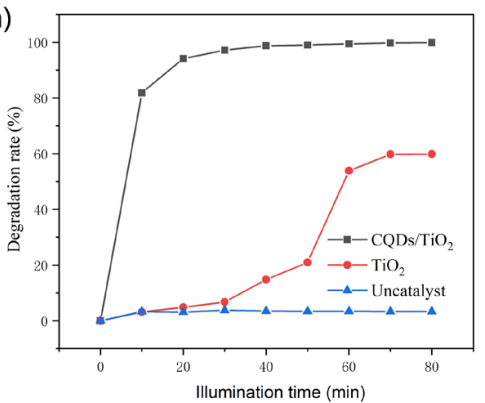

(c)

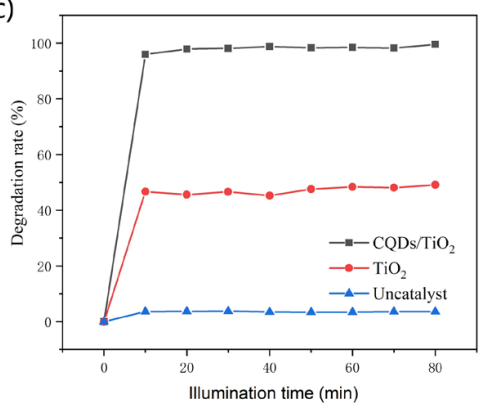

(b)

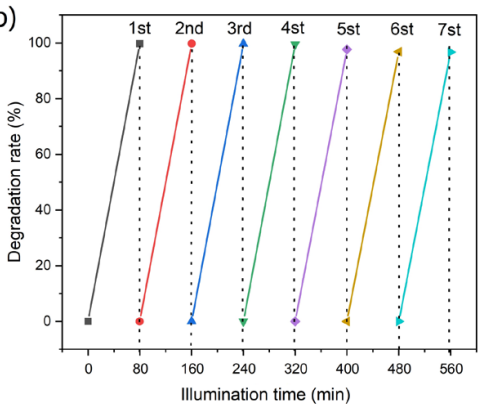

(d)

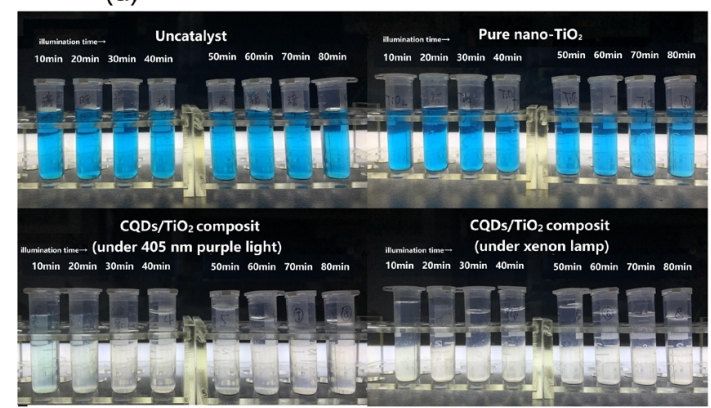

Figure 8. (a) The photocatalytic degradation rate of $\mathrm{CQDs} / \mathrm{TiO}_{2}$ composite and pure $\mathrm{TiO}_{2}$ to methylene blue within different irradiation times under $405 \mathrm{~nm}$ purple light; (b) the photocatalytic degradation 
rate of $\mathrm{CQDs} / \mathrm{TiO}_{2}$ composite of the different photocatalytic cycle with $80 \mathrm{~min}$ as a working cycle; (c) the photocatalytic degradation rate of $\mathrm{CQDs} / \mathrm{TiO}_{2}$ composite and pure $\mathrm{TiO}_{2}$ methylene blue within different irradiation time under a xenon lamp; (d) the photographs showing the photocatalytic degradation effects on methylene blue of $\mathrm{CQDs} / \mathrm{TiO}_{2}$ composite and pure $\mathrm{TiO}_{2}$.

Under natural light (simulated by a xenon lamp), $\mathrm{CQDs} / \mathrm{TiO}_{2}$ based on $\mathrm{WRN}$ also showed better photocatalytic performance than that of pure $\mathrm{TiO}_{2}$. The degradation rate of pure $\mathrm{TiO}_{2}$ within 10 and 80 min was 46.71 and $49.12 \%$, respectively, which could not achieve complete degradation. By contrast, the degradation rate of CQDs $/ \mathrm{TiO}_{2}$ could be up to $95.95 \%$ within $10 \mathrm{~min}$ and $99.54 \%$ within $80 \mathrm{~min}$, which was even better than that under $405 \mathrm{~nm}$ purple light (see Figure 8c).

As shown in Figure 9, the resulting $\mathrm{CQDs} / \mathrm{TiO}_{2}$ composite displayed a high efficient photocatalytic degradation effect on other common water-soluble dyes such as malachite green, methyl violet, basic fuchsin, and rhodamine B under visible light irradiation and showed better photocatalytic performance than that of commercial $\mathrm{TiO}_{2}$. Among them, the degradation rate of $\mathrm{CQDs} / \mathrm{TiO}_{2}$ composite of malachite green and methyl violet could reach up to $99 \%$ within $10 \mathrm{~min}$, which indicated that this composite displayed a very high photocatalytic degradation effect on triphenylmethane dye (See Figure 9a,b). It was also observed that the $\mathrm{CQDs} / \mathrm{TiO}_{2}$ composite could be used against some dyes with good photobleaching resistance. For example, rhodamine B was almost undegradable under $405 \mathrm{~nm}$ purple light with the existence of pure $\mathrm{TiO}_{2}$, but the $\mathrm{CQDs} / \mathrm{TiO}_{2}$ composite could degrade $99 \%$ rhodamine B within 30 min (see Figure 9d). Furthermore, due to the very low cost of CQDs based on WRN, the CQDs $/ \mathrm{TiO}_{2}$ composite based on WRN could also achieve a lower cost than that of commercial $\mathrm{TiO}_{2}$, which could be a good substitute for commercial $\mathrm{TiO}_{2}$ and had good application in organic water pollution control. In addition, the photocatalytic degradation processes of the dyes by $\mathrm{CQDs} / \mathrm{TiO}_{2}$ composite all accorded with the Langmuir Hinshelwood kinetic model, whose apparent constant $\left(\mathrm{K}_{\mathrm{app}}\right)$ values and regression coefficients are presented in Table 7 . The $\mathrm{K}_{\mathrm{app}}$ values displayed a range of methyl violet $>$ malachite green $>$ rhodamine $\mathrm{B}>$ methylene blue $>$ basic fuchsin.

(a)

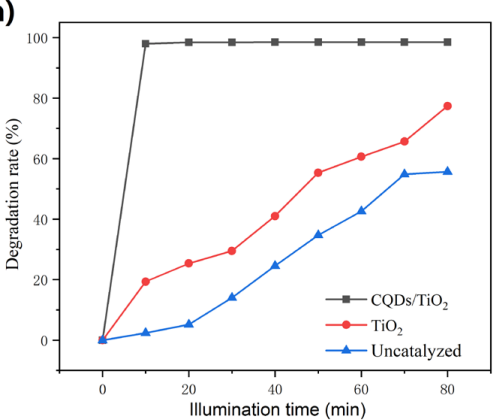

(c)

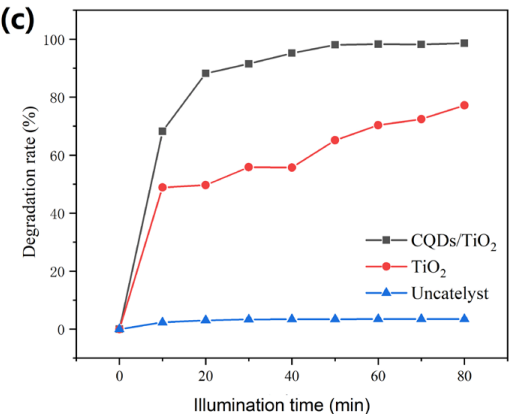

(b)

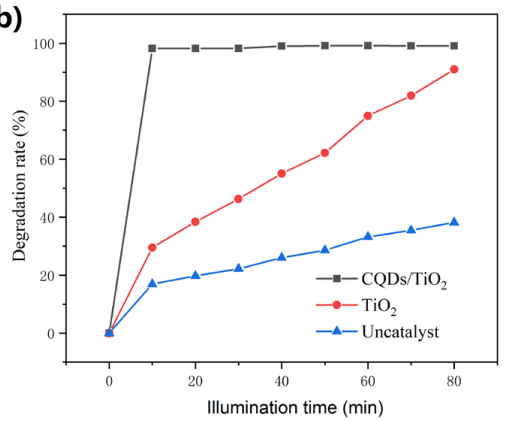

(d)

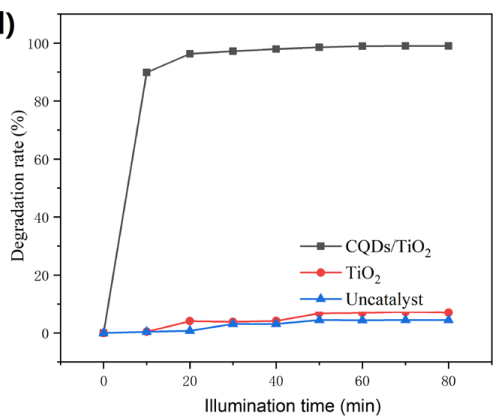

Figure 9. The photocatalytic degradation rate of $\mathrm{CQDs} / \mathrm{TiO}_{2}$ composite and pure $\mathrm{TiO}_{2}$ to malachite green (a) methyl violet (b), basic fuchsin (c), and rhodamine B (d) within different irradiation times under $405 \mathrm{~nm}$ purple light. 
Table 7. The kinetic adsorption parameters obtained using pseudo-first-order for the photocatalytic degradation of various dyes under $405 \mathrm{~nm}$ purple light.

\begin{tabular}{ccc}
\hline Dyes & $\mathbf{K}_{\text {app }}\left(\mathbf{m i n}^{-1}\right)$ & $\mathbf{R}^{\mathbf{2}}$ \\
\hline methylene blue & $0.1238 \pm 0.0237$ & 0.9967 \\
malachite green & $0.2586 \pm 0.0104$ & 0.9935 \\
methyl violet & $0.3032 \pm 0.0082$ & 0.9971 \\
basic fuchsin & $0.1199 \pm 0.0032$ & 0.9971 \\
rhodamine B & $0.1949 \pm 0.0067$ & 0.9953 \\
\hline
\end{tabular}

In order to further export the photocatalytic mechanism of the as-prepared $\mathrm{CQDs} / \mathrm{TiO}_{2}$ composite based on WRN, the UV-VIS absorption spectra of the pure $\mathrm{TiO}_{2}$ and $\mathrm{CQDs} / \mathrm{TiO}_{2}$ composite were tested and shown in Figure 10a. The absorption of the pure $\mathrm{TiO}_{2}$ was mainly in the UV region, and there was almost no absorption in the wavelength range above $430 \mathrm{~nm}$. In contrast, the CQDs $/ \mathrm{TiO}_{2}$ composite exhibited a wide visible-light absorption region and enhanced light-absorption intensity. Thus, the combination of CQDs and $\mathrm{TiO}_{2}$ could effectively enhance the energy absorption and produce more electron-hole pairs in the visible light region. Furthermore, the band gaps of the pure $\mathrm{TiO}_{2}$ and $\mathrm{CQDs} / \mathrm{TiO}_{2}$ samples were calculated by means of Kubelka-Munk theory [51] and shown in Figure 10b. The band gap of the pure $\mathrm{TiO}_{2}$ photocatalyst was about $3.07 \mathrm{eV}$. By comparison, the introduction of CQDs could afford a narrower band gap of $1.55 \mathrm{eV}$, which could promote the electronic transition and improve the photocatalytic degradation process. This feature of the CQDs $/ \mathrm{TiO}_{2}$ composite was also proven by photocurrent response with on/off cycles of visible light irradiation (Figure 10c). It could be observed that the CQDs $/ \mathrm{TiO}_{2}$ electrode displayed a much higher photocurrent (more than 60 times) in comparison to the pure $\mathrm{TiO}_{2}$ electrode upon irradiation. This means that a faster interfacial charge transfer to the electron acceptor occured in the $\mathrm{CQDs} / \mathrm{TiO}_{2}$ composite, which resulted in the more effective separation of electron-hole pairs. On the other hand, the steady-state PL spectra of the pure $\mathrm{TiO}_{2}$ and $\mathrm{CQDs} / \mathrm{TiO}_{2}$ composite (Figure 10d) showed that the emission intensity of the CQDs $/ \mathrm{TiO}_{2}$ composite was much lower than that of pure $\mathrm{TiO}_{2}$ at similar emission, which suggested that the modification of CQDs could effective reduce the recombination of electron-hole pairs.

The ESR spin-trap with the DMPO technique was used to investigate the reactive oxygen species generated by the CQDs $/ \mathrm{TiO}_{2}$ composite or pure $\mathrm{TiO}_{2}$ photocatalysts. As shown in Figure 11a,b, obvious characteristic peaks of both superoxide radical $\left(\mathrm{O}_{2}{ }^{-}\right)$and hydroxyl radical $(\cdot \mathrm{OH})$ of $\mathrm{DMPO}$ was observed by using the $\mathrm{CQDs} / \mathrm{TiO}_{2}$ composite as a photocatalyst, which suggested that the $\mathrm{CQDs} / \mathrm{TiO}_{2}$ composite could reduce adsorbed $\mathrm{O}_{2}$ to form $\mathrm{O}_{2}{ }^{-}$radical and oxidize adsorbed $\mathrm{H}_{2} \mathrm{O}$ or $\mathrm{OH}^{-}$to form $\cdot \mathrm{OH}$ radical under light radiation. Moreover, compared with using pure $\mathrm{TiO}_{2}$ as a photocatalyst, signals of both $\mathrm{O}_{2} \cdot{ }^{--}$and $\cdot \mathrm{OH}$ radical of DMPO with $\mathrm{CQDs} / \mathrm{TiO}_{2}$ composite were evidently stronger (Figure 11c,d). Thus the CQDs $/ \mathrm{TiO}_{2}$ composite displayed stronger abilities in producing $\mathrm{O}_{2}{ }^{-}$and $\cdot \mathrm{OH}$ radical than that of pure $\mathrm{TiO}_{2}$ on the same test condition, which demonstrates that the introduction of CQDs could result in efficient electron-hole pair separation and enable more photogenerated electrons to reduce $\mathrm{O}_{2}$ and more photogenerated holes to oxidize $\mathrm{H}_{2} \mathrm{O}$ or $\mathrm{OH}^{-}$. Based on the results of photodegradation and reactive oxygen species during the degradation process, possible photocatalytic mechanism schematics was illustrated in Figure 11e. When the $\mathrm{CQDs} / \mathrm{TiO}_{2}$ composite was irradiated by visible light, the CQDs can be easily excited with photogenerated electrons on the conduction band (CB) and leave the holes on the valence band (VB). The photogenerated hole could react with $\mathrm{H}_{2} \mathrm{O}$ or $\mathrm{OH}^{-}$to produce more $\cdot \mathrm{OH}$. The excited electrons could spatial transfer to the $\mathrm{TiO}_{2}$ quickly and result in a more efficient electron-hole pair separation. After that, the separated electrons on the CQDs could react with $\mathrm{O}_{2}$ to produce more $\mathrm{O}_{2}{ }^{--}$. The generated $\mathrm{O}_{2}{ }^{--}$ and $\mathrm{OH}$ radical play the main role in the photodegradation process, causing excellent photocatalytic activity. 
(a)
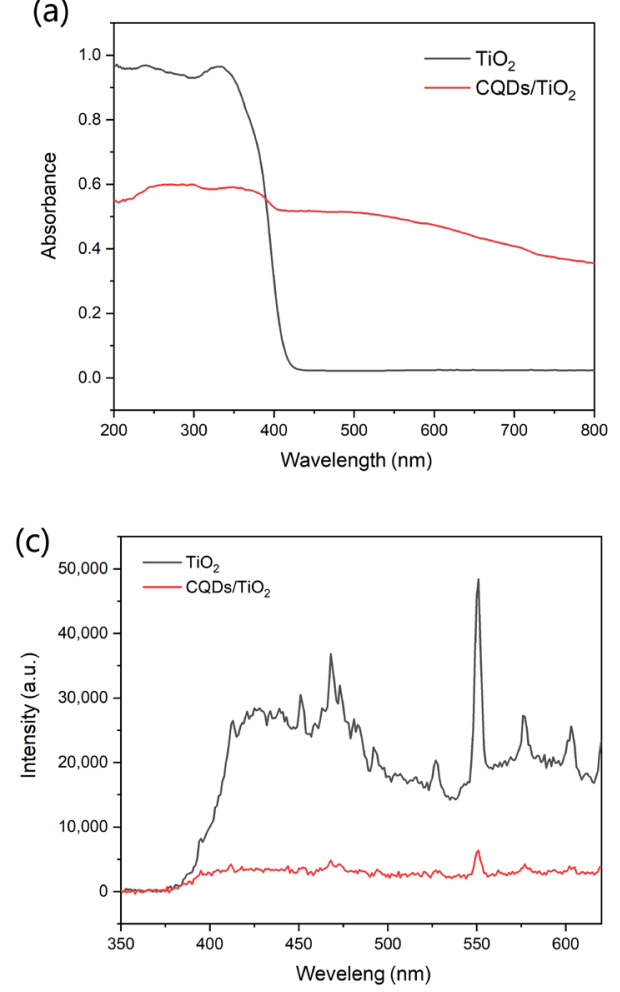

(b)

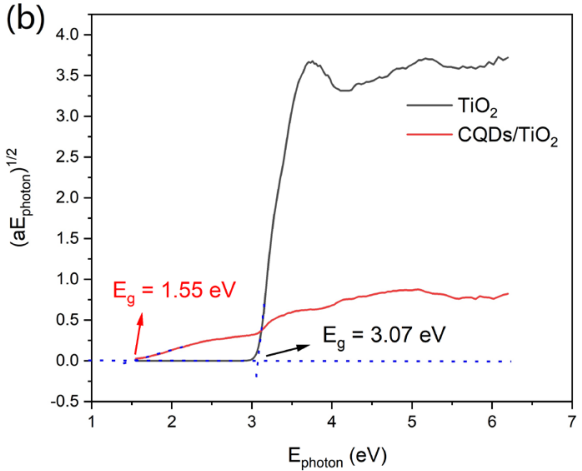

(d)

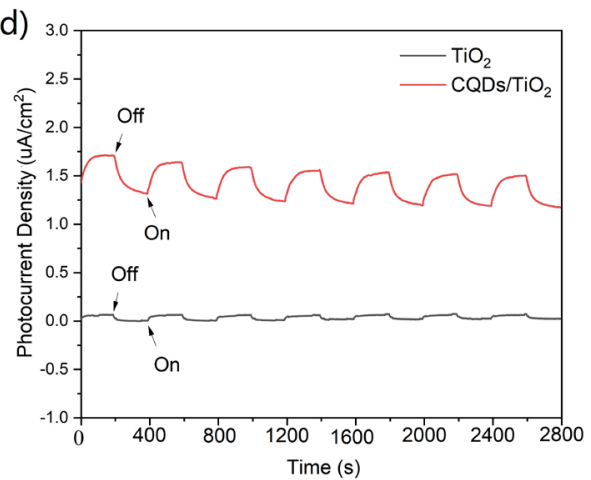

Figure 10. (a) The UV-VIS absorption spectra of $\mathrm{CQDs} / \mathrm{TiO}_{2}$ composite and pure $\mathrm{TiO}_{2}$; (b) the $\left(a E_{\text {photon }}\right)_{1 / 2}$ vs. $E_{\text {photon }}$ curves of CQDs $/ \mathrm{TiO}_{2}$ composite and pure $\mathrm{TiO}_{2} ;$ (c) the PL spectra of CQDs / / $\mathrm{TiO}_{2}$ composite and pure $\mathrm{TiO}_{2} ;(\mathbf{d})$ the photocurrent response of $\mathrm{CQDs} / \mathrm{TiO}_{2}$ composite and pure $\mathrm{TiO}_{2}$.
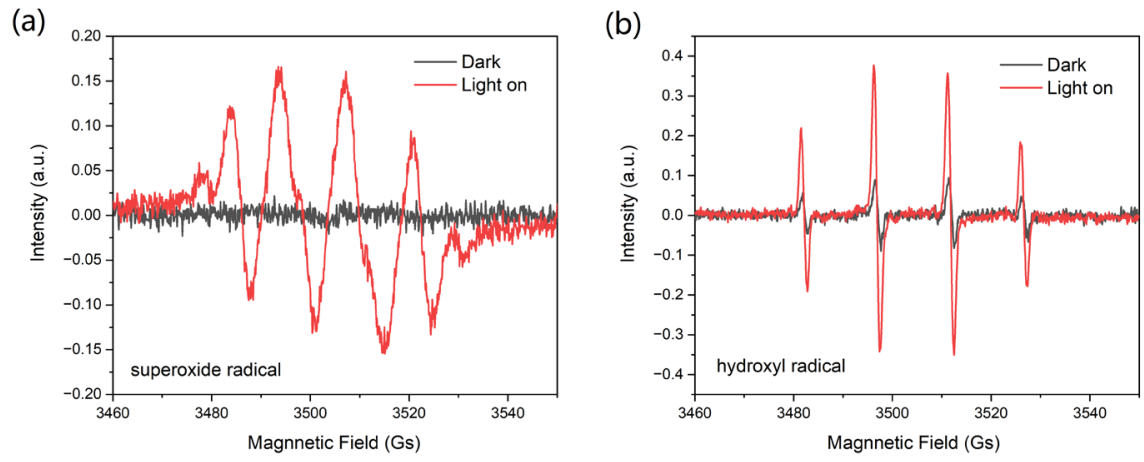

Figure 11. Cont. 

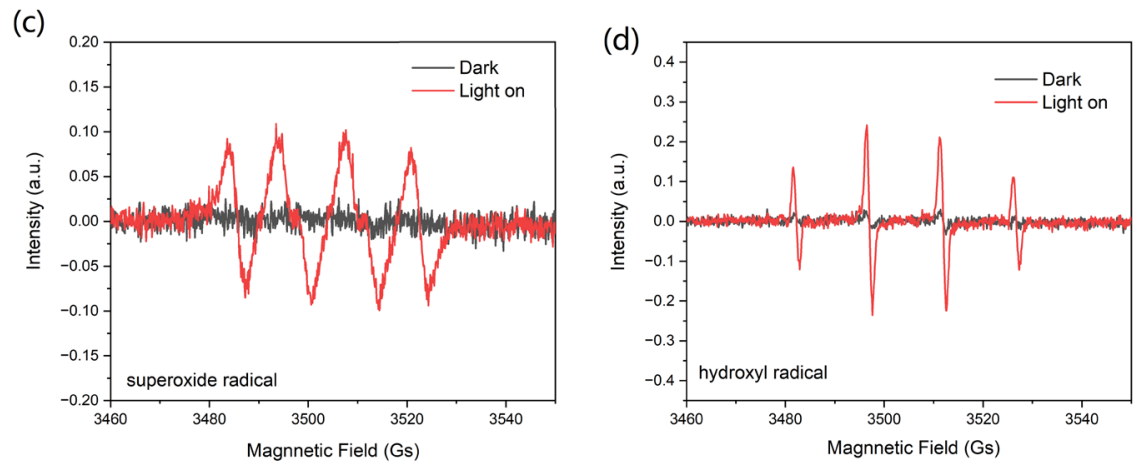

(e)

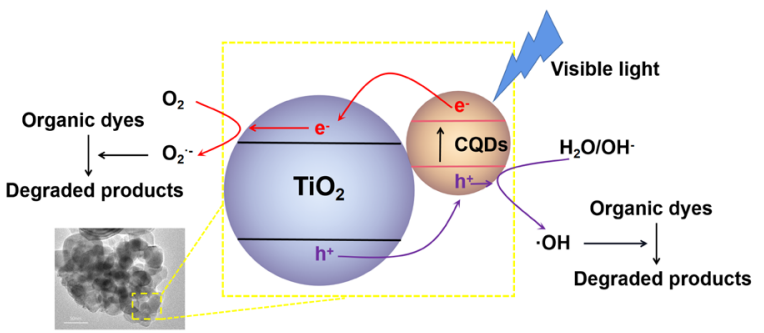

Figure 11. (a,b) DMPO spin-trapping ESR spectra of $\mathrm{CQDs} / \mathrm{TiO}_{2}$ composite in methanol (a) and water (b) under visible light irradiation; (c,d) DMPO spin-trapping ESR spectra of pure $\mathrm{TiO}_{2}$ in methanol (c) and water (d) under visible light irradiation; (e) schematic illustration of the photocatalytic mechanism CQDs $/ \mathrm{TiO}_{2}$ composite.

\section{Conclusions}

In this paper, low-cost $\mathrm{AC}$ and $\mathrm{CQDs} / \mathrm{TiO}_{2}$ composite were simultaneously synthesized by using WRN as raw material. During the synthesis process, the intermediate mixture after hydrothermal carbonization was divided into two parts: the precipitate (HTC powder) was used to produce AC, while the liquid part (CQDs solution) could acquire synthesized CQDs $/ \mathrm{TiO}_{2}$ composite simultaneously. Both of the two materials showed potential applications in water pollution control. The AC could absorb heavy metal ions efficiently, while the $\mathrm{CQDs} / \mathrm{TiO}_{2}$ composite displayed a high efficient photocatalytic degradation effect on various water-soluble dyes, which showed better photocatalytic performance than commercial $\mathrm{TiO}_{2}$, which could form a low-cost waste-water treatment system together with AC. Compared with other recycling methods for catering waste, the method described in this paper could achieve the full utilization of WRN without secondary pollution and could produce about $43 \mathrm{~g} \mathrm{AC}$ and $29 \mathrm{~g}$ CQDs $/ \mathrm{TiO}_{2}$ composite for each kilogram of WRN. On the other hand, the $\mathrm{AC}$ or $\mathrm{CQDs} / \mathrm{TiO}_{2}$ composite based on WRN could realize higher added value than conventional products like feed, a fact that suggests broad prospects for industrialization and could provide a new method for the recycling of cooking waste.

Supplementary Materials: The following supporting information can be downloaded at: https: / / www.mdpi.com/article/10.3390/nano12030472/s1. Figure S1: (a) Fluorescence response of different concentrations of $\mathrm{Fe}^{3+}$ solution to CQDs based on WRN; (b) Linear relationship between fluorescence response of CQDs and $\mathrm{Fe}^{3+}$ solution concentration; Figure S2: The SEM image of HTC; Figure S3: The TG curves of HTC and AC based on WRN; Figure S4: $(\mathbf{a}, \mathbf{b})$ : The nitrogen adsorption/desorption isotherms (a) and pore size distribution curves (b) of $\mathrm{AC}$ after $\mathrm{Pb}$ (II) adsorption; $(\mathbf{c}, \mathbf{d})$ : The nitrogen adsorption/desorption isotherms (c) and pore size distribution curves (d) of AC after $\mathrm{Cr}(\mathrm{VI})$ adsorption; Figure S5: The PZC of HTC (a), AC (b), AC after Pb(II) adsorption (c) and $\mathrm{AC}$ after $\mathrm{Cr}(\mathrm{VI})$ adsorption (d); Figure S6: PXRD patterns of $\mathrm{CQDs} / \mathrm{TiO}_{2}$ composite and pure nano- $\mathrm{TiO}_{2}$ powder; Figure S7: (a) The photocatalytic degradation rate of $\mathrm{CQDs} / \mathrm{TiO}_{2}$ composites with different carbon contents and pure $\mathrm{TiO}_{2}$ to methylene blue within different irradiation times under $405 \mathrm{~nm}$ purple light; (b) The partial enlargement of (a) showing the degradation rates of $\mathrm{CQDs} / \mathrm{TiO}_{2}$ composites with different carbon content to methylene blue; Figure S8: The kinetic fitting 
of photocatalytic degradation of $\mathrm{CQDs} / \mathrm{TiO}_{2}$ composite to methylene blue (a), malachite green (b), methyl violet (c), basic fuchsin (d) and rhodamine B (e) under $405 \mathrm{~nm}$ purple light; Table S1: The optimization of the experimental conditions of AC; Table S2: Experimental conditions of CQDs/ $\mathrm{TiO}_{2}$ composite based on WRN.

Author Contributions: Methodology \& writing: original draft preparation, X.J.; Software: R.C.; Investigation: J.L., Y.J. and X.C.; resources: Y.L.; data curation: J.Y.; Writing: review and editing \& project administration, S.C.; Funding acquisition \& supervision, H.S. All authors have read and agreed to the published version of the manuscript.

Funding: This research was funded by by grants of National Nature Science Foundation of China (No. 51763007), Guangxi Natural Science Foundation Program (No. 2015GXNSFBA139033), Basic Ability Improvement Program for Guangxi Young and Middle-aged Teachers (No. KY2016YB186), Sharing Foundation of Guangxi Key Laboratory of Optical and Electronic Materials and Devices (No. 20 AA-15 and 20 AA-9), as well as Sharing Foundation of Guangxi Key Laboratory of Geomechanics and Geotechnical Engineering (No. 17-J-21-7).

Institutional Review Board Statement: Not applicable.

Informed Consent Statement: Not applicable.

Data Availability Statement: Not applicable.

Conflicts of Interest: The authors declare no conflict of interest.

\section{References}

1. Albizzati, P.F.; Tonini, D.; Astrup, T.F. A Quantitative Sustainability Assessment of Food Waste Management in the European Union. Environ. Sci. Technol. 2021, 160, 104854. [CrossRef] [PubMed]

2. Baul, T.K.; Sarker, A.; Nath, T.K. Restaurants' waste in Chittagong city, Bangladesh: Current management, awareness on environmental hazard and perception towards potential uses. J. Clean. Prod. 2021, 292, 126073. [CrossRef]

3. Joshi, P.; Visvanathan, C. Sustainable management practices of food waste in Asia: Technological and policy drivers. J. Environ Manag. 2019, 247, 538-550. [CrossRef] [PubMed]

4. Hu, C.; Yan, B.; Wang, K.-j.; Xiao, X.-m. Modeling the performance of anaerobic digestion reactor by the anaerobic digestion system model (ADSM). J. Environ. Chem. Eng. 2018, 6, 2095-2104. [CrossRef]

5. Jeison, D. Anaerobic digestion: Closing cycles for sustainability. Rev. Environ. Sci. Biol. 2015, 14, 535-536. [CrossRef]

6. Meegoda, J.N.; Li, B.; Patel, K.; Wang, L.B. A Review of the Processes, Parameters, and Optimization of Anaerobic Digestion. Int. J. Environ. Res. Public Health 2018, 15, 2224. [CrossRef]

7. Nakamura, S. Tracking the Product Origins of Waste for Treatment Using the WIO Data Developed by the Japanese Ministry of the Environment. Environ. Sci. Technol. 2020, 54, 14862-14867. [CrossRef]

8. Shangguan, H.; Fu, T.; Wu, J.; Tang, J.; Zeng, R.J.; Zhou, S. Use of an in situ thermoelectric generator for electric field-assisted aerobic composting. Sci. Total Environ. 2020, 742, 140618. [CrossRef]

9. Luo, H.; Zeng, Y.; Cheng, Y.; He, D.; Pan, X. Recent advances in municipal landfill leachate: A review focusing on its characteristics, treatment, and toxicity assessment. Sci. Total Environ. 2020, 703, 135468. [CrossRef]

10. Wang, Y.; Levis, J.W.; Barlaz, M.A. Life-Cycle Assessment of a Regulatory Compliant U.S. Municipal Solid Waste Landfill. Environ. Sci. Technol. 2021, 55, 13583-13592. [CrossRef]

11. Zhang, P.; Liu, H.; Jiang, X.; Lv, H.; Cui, C.; Huyan, Z. Numerical Model of Leachate Recirculation in Bioreactor Landfills with High Kitchen Waste Content. Water 2021, 13, 1750. [CrossRef]

12. Tang, Y.; You, F. Multicriteria Environmental and Economic Analysis of Municipal Solid Waste Incineration Power Plant with Carbon Capture and Separation from the Life-Cycle Perspective. ACS Sustain. Chem. Eng. 2017, 6, 937-956. [CrossRef]

13. Xiong, X.; Yu, I.K.M.; Tsang, D.C.W.; Bolan, N.S.; Sik Ok, Y.; Igalavithana, A.D.; Kirkham, M.B.; Kim, K.-H.; Vikrant, K. Valueadded chemicals from food supply chain wastes: State-of-the-art review and future prospects. Chem. Eng. J. 2019, $375,121983$. [CrossRef]

14. Ipiales, R.P.; de la Rubia, M.A.; Diaz, E.; Mohedano, A.F.; Rodriguez, J.J. Integration of Hydrothermal Carbonization and Anaerobic Digestion for Energy Recovery of Biomass Waste: An Overview. Energy Fuels 2021, 35, 17032-17050. [CrossRef]

15. Kannan, S.; Gariepy, Y.; Raghavan, G.S.V. Conventional Hydrothermal Carbonization of Shrimp Waste. Energy Fuels 2018, 32, 3532-3542. [CrossRef]

16. Fu, M.M.; Mo, C.H.; Li, H.; Zhang, Y.N.; Huang, W.X.; Wong, M.H. Comparison of physicochemical properties of biochars and hydrochars produced from food wastes. J. Clean. Prod. 2019, 236, 117637. [CrossRef]

17. Yahia, S.H.; Lee, K.K.; Ayed, B.; Hedin, N.; Church, T.L. Activated Carbons from Hydrochars Prepared in Milk. Sci. Rep. 2019, 9 , 16956. [CrossRef] 
18. Milrad, A.A.; Ramadurai, M.; Raghunandhakumar, S.; Krishna, S.G.; Prabhu, P.; Anuradha, D.; Abbas, S. Ultra-radiant photoluminescence of glutathione rigidified reduced carbon quantum dots ( $r$-CQDs) derived from ice-biryani for in vitro and in vivo bioimaging applications. Colloids Surf. A 2020, 586, 124266.

19. Wong, S.; Ngadi, N.; Inuwa, I.M.; Hassan, O. Recent advances in applications of activated carbon from biowaste for wastewater treatment: A short review. J. Clean. Prod. 2018, 175, 361-375. [CrossRef]

20. Goel, J.; Kadirvelu, K.; Rajagopal, C.; Garg, K. Removal of lead(II) by adsorption using treated granular activated carbon: Batch and column studies. J. Hazard. Mater. 2005, 125, 211-220. [CrossRef]

21. Babel, S.; Kurniawan, T.A. Cr(VI) removal from synthetic wastewater using coconut shell charcoal and commercial activated carbon modified with oxidizing agents and/or chitosan. Chemosphere 2004, 54, 951-967. [CrossRef] [PubMed]

22. Bansode, R.R.; Losso, J.N.; Marshall, W.E.; Rao, R.M.; Portier, R.J. Adsorption of metal ions by pecan shell-based granular activated carbons. Bioresour. Technol. 2003, 89, 115-119. [CrossRef]

23. Al-Othman, Z.A.; Ali, R.; Naushad, M. Hexavalent chromium removal from aqueous medium by activated carbon prepared from peanut shell: Adsorption kinetics, equilibrium and thermodynamic studies. Chem. Eng. J. 2012, 184, 238-247. [CrossRef]

24. Abdulkarim, M.; Al-Rub, F.A. Adsorption of lead ions from aqueous solution onto activated carbon and chemically-modifified activated carbon prepared from date pits. Adsorp. Sci. Technol. 2004, 22, 119-134. [CrossRef]

25. Imamoglu, M.; Tekir, O. Removal of copper (II) and lead (II) ions from aqueous solutions by adsorption on activated carbon from a new precursor hazelnut husks. Desalination 2008, 228, 108-113. [CrossRef]

26. Vennilamani, N.; Kadirvelu, K.; Sameena, Y.; Pattabhi, S. Utilization of Activated Carbon Prepared from Industrial Solid Waste for the Removal of Chromium(VI) Ions from Synthetic Solution and Industrial Effluent. Adsorpt. Sci. Technol. 2005, 23, 145-160. [CrossRef]

27. Gorzin, F.; Bahri Rasht Abadi, M.M. Adsorption of $\mathrm{Cr}(\mathrm{VI})$ from aqueous solution by adsorbent prepared from paper mill sludge: Kinetics and thermodynamics studies. Adsorpt. Sci. Technol. 2017, 36, 149-169. [CrossRef]

28. Wang, L.; Zhang, J.; Zhao, R.; Li, Y.; Li, C.; Zhang, C. Adsorption of Pb(II) on activated carbon prepared from Polygonum orientale Linn.: Kinetics, isotherms, pH, and ionic strength studies. Bioresour. Technol. 2010, 101, 5808-5814. [CrossRef] [PubMed]

29. Giri, A.M.; Patel, R.; Mandal, S. Removal of Cr (VI) from aqueous solution by Eichhornia crassipes root biomass-derived activated carbon. Chem. Eng. J. 2012, 185-186, 71-81. [CrossRef]

30. Horikoshi, S.; Serpone, N. Can the photocatalyst $\mathrm{TiO}_{2}$ be incorporated into a wastewater treatment method? Background and prospects. Catal. Today 2020, 340, 334-346. [CrossRef]

31. Wang, C.-C.; Wang, X.; Liu, W. The synthesis strategies and photocatalytic performances of $\mathrm{TiO}_{2} / \mathrm{MOFs}$ composites: A state-ofthe-art review. Chem. Eng. J. 2020, 391, 123601. [CrossRef]

32. Zhang, Y.; Zhang, H.; Tian, S.; Zhang, L.; Li, W.; Wang, W.; Yan, X.; Han, N.; Zhang, X. The Photocatalysis-Enhanced TiO ${ }_{2} @ H P A N$ Membrane with High $\mathrm{TiO}_{2}$ Surface Content for Highly Effective Removal of Cationic Dyes. Langmuir 2021, 37, 9415-9428. [CrossRef] [PubMed]

33. Iravani, S.; Varma, R.S. Green synthesis, biomedical and biotechnological applications of carbon and graphene quantum dots. A review. Environ. Chem. Lett. 2020, 18, 703-727. [CrossRef] [PubMed]

34. Long, C.; Jiang, Z.; Shangguan, J.; Qing, T.; Zhang, P.; Feng, B. Applications of carbon dots in environmental pollution control: A review. Chem. Eng. J. 2021, 406, 126848. [CrossRef]

35. Rasal, A.S.; Yadav, S.; Yadav, A.; Kashale, A.A.; Manjunatha, S.T.; Altaee, A.; Chang, J.-Y. Carbon Quantum Dots for Energy Applications: A Review. ACS Appl. Nano Mater. 2021, 4, 6515-6541. [CrossRef]

36. Marković, Z.M.; Jovanović, S.P.; Mašković, P.Z.; Mojsin, M.M.; Stevanović, M.J.; Danko, M.; Micusik, M.; Jovanović, D.J.; Kleinová, A.; Špitalský, Z.; et al. Graphene oxide size and structure pro-oxidant and antioxidant activity and photoinduced cytotoxicity relation on three cancer cell lines. J. Photochem. Photobiol. B 2019, 10, 111647. [CrossRef] [PubMed]

37. Wang, T.; Liu, X.; Ma, C.; Zhu, Z.; Liu, Y.; Liu, Z.; Wei, M.; Zhao, X.; Dong, H.; Huo, P.; et al. Bamboo prepared carbon quantum dots (CQDs) for enhancing $\mathrm{Bi}_{3} \mathrm{Ti}_{4} \mathrm{O}_{12}$ nanosheets photocatalytic activity. J. Alloys Compd. 2018, 752, 106-114. [CrossRef]

38. Duo, F.; Wang, Y.; Fan, C.; Zhang, X.; Wang, Y. Enhanced visible light photocatalytic activity and stability of CQDs/BiOBr composites: The upconversion effect of CQDs. J. Alloys Compd. 2016, 685, 34-41. [CrossRef]

39. Syed, N.; Huang, J.; Feng, Y. CQDs as emerging trends for future prospect in enhancement of photocatalytic activity. Carbon Lett. 2021. [CrossRef]

40. Pan, J.; Sheng, Y.; Zhang, J.; Wei, J.; Huang, P.; Zhang, X.; Feng, B. Preparation of carbon quantum dots/ TiO 2 nanotubes composites and their visible light catalytic applications. J. Mater. Chem. A 2014, 2, 18082-18086. [CrossRef]

41. Yu, J.; Zhang, C.; Yang, Y.; Yi, G.; Fan, R.; Li, L.; Xing, B.; Liu, Q.; Jia, J.; Huang, G. Lignite-derived carbon quantum dot/TiO 2 heterostructure nanocomposites: Photoinduced charge transfer properties and enhanced visible light photocatalytic activity. New J. Chem. 2019, 43, 18355-18368. [CrossRef]

42. Zhang, J.; Xu, J.; Tao, F. Interface Modification of $\mathrm{TiO}_{2}$ Nanotubes by Biomass-Derived Carbon Quantum Dots for Enhanced Photocatalytic Reduction of $\mathrm{CO}_{2}$. ACS Appl. Energy Mater. 2021, 4, 13120-13131. [CrossRef]

43. Yang, J.; Jin, X.Y.; Liu, Y.; Chen, S.P. Synthesis and Mechanical Properties of C/PLA 3D Printing composites Based on Waste Rice Noodles. Res. Appl. Mater. Sci. 2021, 3, 30-33.

44. Yang, J.; Liu, Y.; Jin, X.Y.; Chen, S.P. Synthesis and properties of fluorescent CQDs/PLA 3D printing composites based on waste rice noodles. IOSR J. Appl. Chem. 2020, 13, 1-5. 
45. Balasubramanian, R.; Perumal, S.V.; Vijayaraghavan, K. Equilibrium isotherm studies for the multi-component adsorption of lead, zinc, and cadmium onto Indonesian peat. Ind. Eng. Chem. Res. 2009, 48, 2093-2099. [CrossRef]

46. Shin, K.Y.; Hong, J.Y.; Jang, J. Heavy metal ion adsorption behavior in nitrogen-doped magnetic carbon nanoparticles: Isotherms and kinetic study. J. Hazard. Mater. 2011, 190, 36-44. [CrossRef]

47. McKay, G.; Bino, M.J.; Altamemi, A.R. The adsorption of various pollutants from aqueous solutions on to activated carbon. Water Res. 1985, 19, 491-495. [CrossRef]

48. Kumara, K.V.; Porkodi, K.; Rocha, F. Langmuir-Hinshelwood kinetics-A theoretical study. Catal. Commun. 2008, 9, 82-84. [CrossRef]

49. Jv, X.; Zhao, X.; Ge, H.; Sun, J.; Li, H.; Wang, Q.; Lu, H. Fabrication of a Magnetic Poly (aspartic acid)-Poly (acrylic acid) Hydrogel: Application for the Adsorptive Removal of Organic Dyes from Aqueous Solution. J. Chem. Eng. Data 2019, 64, 1228-1236. [CrossRef]

50. Narula, A.; Rao, C.P. Hydrogel of the Supramolecular Complex of Graphene Oxide and Sulfonatocalix [4] arene as Reusable Material for the Degradation of Organic Dyes: Demonstration of Adsorption and Degradation by Spectroscopy and Microscopy. ACS Omega 2019, 4, 5731-5740. [CrossRef]

51. Zeng, X.; Wang, Z.; Wang, G.; Gengenbach, T.R.; McCarthy, D.T.; Deletic, A.; Yu, J.; Zhang, X. Highly dispersed TiO 2 nanocrystals and WO3 nanorods on reduced graphene oxide: Z-scheme photocatalysis system for accelerated photo catalytic water disinfection. Appl. Catal. B Environ. 2017, 218, 163-173. [CrossRef] 